\title{
Adaptación psicométrica del Módulo de Sintaxis de la Batería de Lenguaje Objetiva y Criterial (BLOC)
}

Sandra Inurritegui G.

El presente estudio tuvo como objetivo analizar la validez y confiabilidad del Módulo de Sintaxis de la Batería de Lenguaje Objetiva y Criterial (BLOC). Se trabajó con 124 participantes de 6, 7 y 8 años, de ambos sexos, divididos en dos grupos: 90 participantes del grupo sin dificultades de lenguaje y 34 del grupo con diagnóstico de dificultades de lenguaje. Los resultados demostraron que los puntajes obtenidos a través del Módulo de Sintaxis de BLOC son confiables. Igualmente, se puede concluir que dicha prueba posee validez de constructo, ya que las correlaciones de cada bloque con el módulo alcanzan valores significativos, la matriz de correlaciones reporta asociaciones significativas entre los bloques y el análisis factorial demuestra la existencia de un factor dominante.

Lenguaje / desarrollo sintáctico / validez / confiabilidad

\section{Psychometric adaptation of the Syntax Module of the Objective and Criterial Language Inventory}

The aim of the current study was to analyze the validity and reliability of the Syntax Module of the Objective and Criterial Language Inventory (BLOC). Participants were 124 children, with ages ranged from 6 to 8 years old, both male and female in two groups: 90 children without language disorders and 34 children with language disorders. Results shown that the scores of the syntax Module of BLOC were reliable. It was also concluded that this test has a construct validity, due to the fact that the item-test correlation for every scale demonstrated to be significant, the correlation matrix reported significant associations between the scales and factor analysis showed that there is one single dominant factor.

Language / syntactic development / validity / reliability 
La importancia del lenguaje en el medio educativo, social y personal, como habilidad ligada a los aprendizajes y a las relaciones interpersonales, ha generado desde hace varias décadas numerosos estudios sobre su adquisición, componentes y uso.

En el terreno educativo, es evidente la importancia del lenguaje como instrumento fundamental para el desarrollo cognitivo y social de los niños, así como para poder responder adecuadamente a las demandas curriculares de cada etapa educativa (Puyuelo, Rondal \& Wiig, 2000).

De acuerdo con Puyuelo (1995) la evaluación psicológica y del lenguaje debe detectar los cambios que se producen en el individuo, así como los distintos ritmos de desarrollo en un mismo individuo o con relación a los de un grupo determinado.

Myers (1987; citado por Puyuelo, Rondal \& Wiig, 2000) resume de la siguiente manera los objetivos generales de la evaluación del lenguaje: Detectar niños o estudiantes que necesitan atención específica, diagnosticar sus problemas, identificar sus necesidades educativas y constatar su evolución como consecuencia de la aplicación de programas especiales.

Siguiendo la orientación de los trabajos de Bloom y Lahey (1978), el análisis del lenguaje se basa en el estudio de forma, contenido y uso. Cada uno corresponde con aspectos psicolingüís- ticos diferentes: forma (fonología, morfología y sintaxis), contenido (semántica) y uso (pragmática).

Actualmente, el número de pruebas de lenguaje existentes en castellano es limitado. Muchas de ellas son de detección, abarcan solo un aspecto del lenguaje, se aplican a un intervalo de edad reducido y algunas son adaptaciones de pruebas elaboradas en otros idiomas, hace diez o veinte años.

En nuestro medio, las pruebas de las que se dispone, como el Test de Vocabulario en Imágenes Peabody (Dunn, 1959), el Test de Conceptos Básicos de Bohem (Bohem, 1969), el Test de Comprensión Auditiva de Carrow y la Prueba de Articulación de Moreno, evalúan solo un aspecto del lenguaje (vocabulario, comprensión de conceptos, aspectos fonológicos o articulación), es decir, miden una de las dimensiones del lenguaje.

Así, podemos ver que no contamos con instrumentos que nos permitan tener una visión global del lenguaje, las pruebas no permiten detectar con profundidad el nivel de los alumnos en cuanto a la forma, contenido y uso del lenguaje, ni seguirlos con un amplio rango de edad.

Una de las pruebas más utilizadas en nuestro medio para valorar el lenguaje en varios de sus aspectos es la Prueba Illinois de Habilidades Psicolingüísticas (ITPA) (McCarthy \& Kirk, 1968) construida como un instrumento diagnóstico 
con el objetivo de poner de manifiesto dificultades de aprendizaje originadas por disfunciones psicolingüísticas. Sin embargo, los resultados del estudio de la validez de la Prueba Illinois de Habilidades Psicolingüísticas (ITPA) realizada por Matos (1998) mostraron que esta carece de validez en los dos aspectos fundamentales estudiados: en el diagnóstico educacional y en la intervención educacional, es decir, en el diseño de programas remediales para superar las dificultades encontradas.

La Batería de Lenguaje Objetiva y Criterial (BLOC), (Puyuelo et al., 1998a), incorpora conceptos actuales en psicolingüística en relación con los diferentes componentes del lenguaje (forma, contenido y uso) y la valoración ligada al contexto, dentro de una perspectiva global de desarrollo.

Con la BLOC se pretende disponer de métodos, técnicas e instrumentos que permitan caracterizar al máximo el lenguaje, valorando tanto aspectos cuantitativos como cualitativos. Se trata de una prueba referida a la edad, pero que proporciona además información sobre diferentes aspectos del lenguaje: morfología, sintaxis, semántica y pragmática.

\section{EL LENGUAJE}

En un intento por comprender lo que los niños aprenden sobre el lenguaje y cómo se puede ayudar a los niños con dificultades de lenguaje, se debe especifi- car los componentes más relevantes para describir el desarrollo del lenguaje y los desórdenes de este. Según Bloom y Lahey (1978), el lenguaje puede ser definido como "un código por el cual se representan ideas sobre el mundo a través de un sistema arbitrario de signos para la comunicación".

Dada la anterior definición de lenguaje, es posible identificar sus tres componentes principales: contenido, forma y uso. Así, el lenguaje conlleva un contenido o significado que es codificado o representado por una forma lingüística para algún propósito o uso en un contexto concreto en particular (Triadó \& Forns, 1989).

La forma del lenguaje puede ser descrita de diversas maneras, según los distintos componentes del propio lenguaje (Bloom \& Lahey, 1978). Si tomamos en cuenta las unidades sonoras nos referimos a la fonología; si se toma en cuenta las unidades de significación o palabras, hablamos de morfología, y si nos referimos a las formas de combinarse una palabra con otra nos referimos a la sintaxis.

\section{LA SINTAXIS}

Sintaxis significa ordenación. Es la parte de la lingüística que da razón de la estructura de las oraciones de una lengua (Martínez Celdrán, 1998).

La sintaxis puede ser definida como "la ciencia, parte de la gramática, que estudia las oraciones gramaticales, 
analizadas en conjunto y a través de los elementos que las constituyen, es decir, se ocupa de las funciones que cumplen las palabras dentro de una expresión" (Fernández, 1990).

El contenido específico de la sintaxis incluye el estudio de las unidades sintácticas: sintagmas y oraciones. Las definiciones de las unidades sintácticas suelen ser controvertidas, pues se producen solapamientos entre ellas debido a que se emplean varios términos (oración, frase, sintagma y enunciado) que pueden dar lugar a confusiones si se desconocen las diferentes interpretaciones (Acosta \& Moreno, 1999).

La palabra sintagma significa grupo. Un sintagma es un grupo de palabras que presenta coherencia desde el punto de vista semántico, sintáctico y fonológico (Martínez Celdrán, 1998).

La oración es la unidad funcional mayor de la sintaxis (Martínez Celdrán, 1998). Se define como la unidad más pequeña con estructura autónoma $y$ de sentido completo en sí misma en que se divide el habla real. Tener sentido completo en sí misma quiere decir que contiene una enunciación (que puede ser afirmativa o negativa), una pregunta, un deseo o un mandato. Así, tenemos que la estructura interna de la oración está constituida por unidades sintácticas inferiores: los constituyentes. Estos poseen una categoría sintáctica: sintagma nominal (SN, cuyo núcleo es un nombre sustantivo); sintagma verbal (SV); sintagma adjetival
(SAdj); y sintagma preposicional (SPrep); y cumplen una función sintáctica: sujeto (S), verbo (V), objeto directo (OD), objeto indirecto (OI), etcétera.

\section{Estructura sintagmática}

La función básica de la sintaxis de las lenguas naturales consiste en combinar distintos elementos léxicos para formar oraciones. Estas están dotadas de una estructura interna jerarquizada que contiene no solo elementos léxicos sino también elementos sintagmáticos o sintagmas.

Como explica Martínez Celdrán (1998), los constituyentes o unidades sintácticas inferiores vienen determinados por una estructura interna (una forma) y unas posibilidades de distribución o aparición en un contexto (una función).

La estructura de los sintagmas como constituyentes inmediatos de la oración, es decir, realizando dentro de ella una función asignada, está comprendida por un núcleo, que es imprescindible, y unos modificadores. Estos son de dos tipos: los especificadores o determinantes (antepuestos al núcleo) y los complementos (que se posponen a él). Todos ellos a su vez pueden ser obligatorios (requeridos por el propio núcleo), especificativos o explicativos. Todo lo que se organiza alrededor de un núcleo, tanto los especificadores como los complementos, es una expansión de este y constituye un sintagma. 
El nombre y el verbo son categorías centrales de la sintaxis de las lenguas naturales en la medida en que ambas representan prototípicamente la expresión material de los dos elementos (argumentos y predicados) pilares de la estructura semántica de una oración. (Fernández \& Anula, 1995). Así, los elementos que integran cualquier oración, de la más simple a la más compleja, se organizan en torno a dos constituyentes: el sintagma nominal y el sintagma verbal. Las categorías léxicas nombre y verbo son los ejes alrededor de los cuales se aglutinan sus expansiones para configurar los SN y SV, respectivamente, y ambos constituyentes ejercen relaciones de dominio sobre las categorías más simples, que se pueden ir segmentando sucesivamente hasta llegar a las palabras.

\section{Funciones sintácticas}

En la mayoría de los enunciados se distinguen tradicionalmente dos partes: el sujeto y el predicado. Los distintos elementos que constituyen las oraciones se ordenan jerárquica y linealmente dependiendo del tipo de relación que se da entre ellos. Tales relaciones son lo que se entiende por función sintáctica y determina la estructura sintáctica de los enunciados.

En toda oración, el verbo establece las relaciones jerárquicas que se van a mantener entre los distintos constituyentes inmediatos. El verbo, por sus características semánticas y sintácticas, asigna a los temas elementos una función dentro de la estructura oracional. Estos grupos funcionales se llaman argumentos.

Cabe diferenciar, según Williams (1980; citado por Martínez Celdrán, 1998), entre argumento externo o sujeto y argumento interno o complementos verbales. El sujeto (argumento externo) establece con el sintagma verbal (SV) una relación de predicación diferente de la que establecen con él los complementos (argumentos internos), los cuales aparecen dentro de la estructura del SV en un nivel inferior. La influencia que el verbo ejerce sobre los argumentos internos es directa; en cambio, la que ejerce sobre el externo o sujeto es indirecta.

El sujeto de una oración es independiente del bloque SV, pero mantiene con él una relación de concordancia de persona y número. Las formas que pueden cumplir la función de sujeto son los sintagmas nominales (SN; "la escuela estará cerrada durante tres días") y las oraciones $(\mathrm{O})$ (cláusulas subordinadas sustantivas) ("Quien llegue primero tendrá preferencia").

Los elementos del sujeto son: el núcleo y los subordinados. El núcleo es el sustantivo o cualquier palabra que cumpla la función nominal (pronombre, adverbio, infinitivo, etcétera). Los subordinados son palabras que acompañan al núcleo y dependen sintácticamente de él. Existen dos clases de subordinados: los modificadores y la 
aposición. Los modificadores son palabras que amplían o limitan el significado del núcleo.

Los elementos del predicado son el núcleo y los modificadores. El núcleo es la palabra más importante del predicado. Es un verbo (simple o compuesto) cuando se trata de un predicado verbal.

Los modificadores son palabras que acompañan al núcleo, dependen sintácticamente de él y sirven para ampliar, precisar, aclarar la significación del verbo. La gramática tradicional los denominó complementos; actualmente se les llama objetos. Se clasifican en:

1. Modificadores monovalentes: Son aquellos que tienen un solo valor, es decir, modifican el verbo y nada más que el verbo. Estos son: objeto directo (OD), objeto indirecto (OI), complemento circunstancial (CC) y agente.

2. Modificador bivalente: Es el que tiene dos valores, es decir, constituye una referencia del verbo y también del sujeto. El único modificador bivalente es el predicativo (llamado también atributo), que aparece obligatoriamente cuando el núcleo del predicado es un verbo copulativo.

\section{La oración compuesta}

Tradicionalmente la oración compuesta se definía como aquella que contiene, por lo menos, dos elementos análogos: dos sujetos, dos verbos (principales o principal y subordinado), etcétera. La gramática actual afirma que la oración compuesta es aquella que está formada por dos o más proposiciones.

Las oraciones compuestas comprenden dos grupos: oraciones compuestas con proposiciones coordinadas y oraciones compuestas con proposiciones subordinadas.

Las oraciones compuestas coordinadas son aquellas que contienen dos o más proposiciones de igual valor sintáctico, es decir, cada proposición es susceptible de adquirir independencia (autonomía) sintáctica. Las proposiciones coordinadas van unidas por un nexo. Por la naturaleza del nexo pueden ser conjuntivas, cuando el nexo es una conjunción y yuxtapuestas, cuando las proposiciones van unidas por un signo de puntuación.

Las oraciones compuestas subordinadas son aquellas que contienen dos o más proposiciones en donde una de ellas (o varias) están en una relación de dependencia sintáctica (con respecto a la proposición principal). Las proposiciones subordinadas pueden construirse dentro del sujeto o dentro del predicado, $\mathrm{y}$ pueden funcionar como sustantivo (proposición subordinada sustantiva), adjetivo (proposición subordinada adjetiva) o adverbio (proposición subordinada adverbial).

\section{DesarRollo sintáctico}

Han sido varios los autores que han intentado caracterizar los patrones evo- 
lutivos de la adquisición de la morfosintaxis. Del Río \& Villaseca (1988, citado por Acosta et al., 1996) ofrece una integración de las descripciones llevadas a cabo por diversos autores distinguiendo cuatro etapas: Prelenguaje (0-12 meses), Primer desarrollo sintáctico (12-30 meses), Expansión gramatical (30-54 meses) y Últimas adquisiciones (> 54 meses).

Clemente (1995) caracteriza el desarrollo sintáctico estableciendo los siguientes periodos: Desarrollo sintáctico inicial (18-24 meses), Expansión sintáctica (24 - 36 meses), Desarrollo sintáctico en edades intermedias (3654 meses) y Últimas adquisiciones (> 54 meses).

Los primeros estudios acerca del desarrollo sintáctico fueron realizados sobre el desarrollo en inglés, pero al estudiar otras lenguas se ha comprobado que la evolución gramatical del niño es muy semejante en todas ellas: comenzando por un periodo de holofrase, el niño pasa a otro periodo en el que expresa ideas por medio de frases telegráficas, hasta llegar a un periodo de desarrollo gramatical propiamente dicho (Clemente, 1995).

Aproximadamente a los 12 meses de edad surge la primera palabra reconocible en la mayor parte de los niños. La mayoría de los investigadores clásicos coinciden en otorgar a este primer estadio de una sola palabra un nivel de no-gramaticalidad así como considerar, en cambio, que ya tiene propiedades adultas de carácter fonológico, semántico y pragmático.

El niño que solo produce una palabra a la vez, no se ve limitado a designar únicamente los objetos, las personas o los hechos. Rápidamente es capaz de producir lo que se denomina holofrases. Una holofrase es un enunciado formado por una sola palabra. Rondal (Puyuelo, Rondal \& Wiig, 2000) considera que el niño pequeño en el estadio de las producciones de una sola palabra, produce elementos aislados que tienen valor de frase. Por ejemplo, el niño que dice "mamá" en presencia del bolso de su madre puede querer transmitir un mensaje del tipo "este es el bolso de mamá", es decir, un enunciado semánticamente más complejo (expresión de una relación de posesión) de lo que parece a simple vista.

\section{Desarrollo sintáctico inicial}

Se considera que se inicia el desarrollo sintáctico cuando el niño, aproximadamente entre los 18 meses y los dos años, empieza a hacer enunciados de dos elementos que ya pueden considerarse con una mínima organización gramatical.

La capacidad de combinar varias palabras en el mismo enunciado aumenta considerablemente el poder expansivo del sistema lingüístico del niño. En primer lugar, la elaboración de mensajes verbales que contienen va- 
rias palabras aumenta considerablemente el valor informativo de los enunciados; en segundo lugar, un enunciado de varias palabras permite la expresión de relaciones de sentido, por ejemplo relaciones de posesión (Puyuelo, Rondal \& Wiig, 2000).

Entre las holofrases y las frases de dos palabras se presenta un periodo transicional llamado secuencias de palabras donde las secuencias de una sola palabra empiezan a aparecer unidas, pero sin la coherencia prosódica que caracteriza a una oración, ya que suele aparecer una pausa entre las dos palabras. El niño produce palabras aisladas sucesivas cuya relación aparece evidente para el observador, ya que tienen que ver con un solo contexto situacional, aunque no se trate de una expresión formal. No tienen el nivel de oraciones porque no tienen orden canónico, hay demasiado tiempo entre palabras y tienen entonación aislada. Algunos autores las denominan "pseudo frases" o "secuencias encadenadas".

Las secuencias de palabras suelen producirse entre los 18 meses y los 2 años, aunque tienen su periodo de más alta frecuencia alrededor de los 20 meses para bajar después a medida que aumenta la producción de oraciones. Estos enunciados se caracterizan por una sucesión de dos palabras, cada una con su contorno de entonación propio y separadas por una pausa de duración variable. La supresión de la pausa entre las palabras y su producción, usando la misma entonación, es decir, bajando la voz solo en la segunda palabra, asegura el paso al estadio de los enunciados de dos palabras, en el que ya existe expresión combinatoria propiamente dicha.

Aproximadamente a los 19 meses aparecen las primeras emisiones de dos palabras y con ellas ya no hay discusión sobre la atribución del nivel morfosintáctico a estos enunciados. Aparece el uso de oraciones negativas mediante el "no" aislado o bien colocándolo al principio o al final del enunciado. Aparecen las primeras interrogativas marcadas con ¿qué? y ¿dónde?

El momento de despegue infantil de la producción de oraciones ya consideradas como tales corresponde con los 24 meses, tiempo en el que los autores registran fuertes incrementos en la cantidad y en la calidad de las producciones. Estas primeras oraciones, aunque irregulares, pobres y sin flexiones morfológicas, tienen organización gramatical.

\section{La combinación de palabras: \\ Expansiones sintácticas}

El niño cognitivamente maduro evoluciona rápidamente y sin esfuerzo, aprendiendo las reglas del lenguaje de sus mayores. Desde los 30 meses aproximadamente la mayoría de los enunciados del niño están correctamente ordenados (Puyuelo, Rondal \& Wiig, 2000).

Como en el inicio del lenguaje, también en estos momentos, el niño antes 
de hacer oraciones largas, gramaticalmente aceptables, pasa por un tiempo en el que emite secuencias de palabras o yuxtaposiciones de secuencias.

Algunos autores llaman a este periodo, habla telegráfica (24-30 meses), ya que las emisiones del niño carecen de elementos relacionantes que les proporcionen corrección gramatical, es decir, no aparecen en ellas las principales palabras-función, tales como artículos, preposiciones, flexiones de género, etcétera, que no formarán parte de sus locuciones hasta el final de esta etapa. Este intervalo de edad se caracteriza por la aparición de secuencias de tres elementos, con una estructura principal de N-V-N (nombre, verbo, nombre).

En cuanto a la forma, Rondal explica que las principales diferencias entre los enunciados de dos o tres palabras del niño y los enunciados del adulto son de dos tipos. Se refieren, por una parte, a las palabras gramaticales (artículos, preposiciones, auxiliares, conjunciones y adverbios) y el marcaje morfológico gramatical. Estos elementos generalmente no aparecen en el lenguaje del niño y por eso se denomina lenguaje telegráfico. Por otra parte, se refieren al marcaje sintáctico de las modalidades del discurso (diferentes tipos de oraciones) (Puyuelo, Rondal \& Wiig, 2000).

Según Clemente (1995), a partir de las frases de dos palabras se producen, entre los 30 y los 36 meses de edad, ex- pansiones que básicamente tienen tres mecanismos:

1. Aumentar alguno de los elementos de las viejas frases de dos palabras; es decir, expandir uno o los dos elementos desdoblándolos de forma que las palabras incrementen el enunciado realizando la misma función semántica.

2. Yuxtaposición de enunciados en la que un solo elemento varía y que juntos formarían un mensaje más largo pero imposible todavía para el niño.

3. Crecimiento progresivo, por el que varios enunciados seguidos van cada uno aumentando su longitud y añadiendo elementos.

De esta manera, en este periodo (30-36 meses), la estructura de la oración se va complejizando, llegándose a combinaciones de cuatro elementos. Empiezan a aparecer las primeras oraciones coordinadas, como por ejemplo "mamá no está y papá no está" (Acosta et al., 1996).

\section{Desarrollo sintáctico en edades intermedias}

Parece ser que la edad de aparición de las primeras conjunciones o partículas conectivas estaría entre los dos y los cuatro años. Entre los 36 y 42 meses el niño aprende la estructura de las oraciones complejas de más de una cláusula con el uso frecuente de la conjunción $y$. Aparecen las subordinadas pero 
y porque, así como el uso rudimentario de los relativos con que. En las oraciones negativas integra la partícula en la estructura de las oraciones (por ejemplo, "el niño no ha dormido"). Los marcadores interrogativos de las oraciones también van complejizándose. El uso prácticamente correcto de los auxiliares ser y haber permiten al niño, en estos momentos, usar el pasado compuesto ("el muñeco ha comido"). Aparecen, asimismo, las perifrásticas del futuro (por ejemplo, "voy a saltar").

Según Clemente (1995), muchos datos expresivos apoyan el uso de conjunciones a los tres años, siendo la más temprana la coordinante "y" seguida por "y entonces". Sin embargo, algunos estudios de Bloom, Lahey, Hood, Lifter \& Fiess (1980; citado por Clemente, 1995) han demostrado que la conectiva " $y$ " se utiliza con numerosos valores semánticos. Su uso pasaría por recorrer valores aditivos, temporales, causales y adversativos.

Las subordinadas aparecen más tarde. Bloom (1978; citado por Clemente, 1995) encuentra diferencias en la aparición de la subordinación: "porque", "que" y "cuando" son las primeras en ser aprendidas, entre los 27 y 36 meses, al igual que "y entonces"; "pero" se utilizó entre los 32 y los 38 meses; "si" y "como" no llegaron a aparecer en todo el periodo de seguimiento (38 meses).

En general, se observa que los niños, llegados a esta edad, han aprendido los recursos esenciales de su lengua, aun- que su abanico de tipos oracionales sigue conteniendo una serie de "errores" desde el punto de vista del adulto, así como una serie de estructuras que necesitan aún cierto aprendizaje. A pesar de ello, en estos momentos de su desarrollo el niño ya puede jugar con su lenguaje y mostrarse creativo con él.

Entre los 42 y los 54 meses, las diversas estructuras gramaticales se van complementando mediante el empleo pronominal, pronombres posesivos, verbos auxiliares, etcétera. Se detecta, en general, una eliminación progresiva de errores sintácticos y morfológicos. Empiezan a aparecer estructuras pasivas, así como otras formas complejas de introducir frases nominales (por ejemplo, "después de", "también") aunque estas estructuras no terminan de consolidarse hasta los nueve o diez años. Se usan correctamente las principales flexiones verbales: presente, futuro (en forma perifrástica) y pasado. Las distintas modalidades del discurso (afirmación, negación, interrogación) se hacen cada vez más complejas. El dominio de las preposiciones también aumenta; se utiliza con frecuencia las del tiempo y las del espacio aunque, en ocasiones, no de forma correcta (Acosta et al., 1996).

\section{Las últimas adquisiciones sintácticas}

La mayoría de los autores suele considerar que después de los cuatro años, lo que queda por aprender respecto a la 
lengua es muy poco, únicamente estructuras muy sofisticadas. El niño mayor de cuatro años domina los aspectos coloquiales de su lengua natural y es capaz de intercambiar ideas, expresar sentimientos, describir sucesos a un nivel muy aceptable respecto a la lengua adulta.

Sin embargo, algunas áreas evolutivas siguen desarrollándose hasta edades tardías. El niño aprende estructuras sintácticas más complejas: pasivas, condicionales, circunstanciales de tiempo, etcétera, y va perfeccionándose en aquellas que ya está familiarizado. Los usos de la voz pasiva y conexiones adverbiales siguen perfeccionándose y generalizándose aunque no llegan a una adquisición completa hasta la edad de siete u ocho años aproximadamente. Hacia los seis años empieza a apreciar los distintos efectos que tiene la lengua al usarla (adivinanzas, chistes, etcétera) y a juzgar la correcta utilización de su propio lenguaje (Acosta et al., 1996).

Lo más relevante que todavía queda por conocer respecto a la propia lengua a niveles tardíos es la utilización correcta de estructuras sintácticas complejas, así como el afianzamiento de habilidades metacognitivas. Este último aspecto es considerado muy importante para el desarrollo de la comprensión.

Rondal (Puyuelo, Rondal \& Wiig, 2000) sostiene que la parataxis (prevalencia de la coordinación en el discurso) parece dominar hasta aproximadamente los cuatro años, edad a partir de la cual se desarrolla la hipotaxis (marcaje formal de la subordinación en el discurso).

A partir de los tres años, más o menos, las subordinadas suelen ir precedidas de lo que se conoce como falsos relativos ("niño que llora") en los que no hay subordinación sino que solo se sitúa el pronombre relativo entre el sujeto y el verbo en la oración. Posteriormente se encuentran construcciones en las que existe subordinación en los hechos, pero en las que el relativo o la conjunción de subordinación no están ("mira el carro ha traído papá"). A continuación aparecen los relativos y las completivas con subordinación bien construida. Las oraciones del relativo que se construyen en este estadio están constituidas casi exclusivamente por elementos preposicionales del sintagma verbal de la proposición principal. De esta manera se sustituyen las estructuras yuxtapuestas y coordinadas ("Oigo al bebé. Está arriba" por "Oigo al bebé que está arriba”). Más adelante el niño producirá oraciones en las que el relativo aparece como constituyente del sintagma nominal sujeto ("El bebé, que está arriba, está a punto de llorar"). Los constituyentes que alargan de forma notable el sintagma nominal sujeto y aumenta el distanciamiento del verbo principal, son más raros incluso en el lenguaje adulto, ya que suponen mayor carga para la memoria a corto plazo (Puyuelo, Rondal \& Wiig, 2000).

Con respecto a las subordinadas circunstanciales parece ser que las cir- 
cunstanciales de causa y consecuencia son las primeras en aparecer alrededor de los cuatro años de edad, y a veces antes ("Él se ha ido porque eres malo").

El paso a la subordinación en el caso de las temporales se realiza entre los cinco y los diez años (Puyuelo, Rondal $\&$ Wiig, 2000). Esta formulación implica que uno de los acontecimientos descritos en la oración compleja se toma como referencia temporal para situar discursivamente el otro acontecimiento, y que los dos hechos descritos están situados el uno con referencia al otro según una relación de simultaneidad, de anterioridad o de posterioridad.

Además, el establecimiento de la relación entre los dos acontecimientos descritos es arbitrario en el sentido de que el orden de las proposiciones puede no estar relacionado con el orden real de los acontecimientos. Por ejemplo, podemos decir indistintamente "Antes de enseñar en Princeton, Einstein era funcionario" o "Einstein era funcionario, antes de enseñar en Princeton". La complejidad de los descubrimientos que deben efectuarse, la de los marcajes léxicosintácticos y la relativa independencia del orden de los acontecimientos referidos resulta un problema para el niño durante un largo periodo de tiempo.

Autores seguidores de Piaget han comprobado la existencia de dificultades en la comprensión infantil de algunos tipos de oraciones que eran solo comprendidas en situaciones limitadas y de forma sobreextendida, sin que el niño llegase a captar el significado total del enunciado, tal como lo haría un adulto.

Sinclair (1967; citado por Clemente, 1995) comprobó cómo ciertos términos comparativos "más que", "menos que", "tanto como", etcétera, no eran usados como términos relacionales hasta que el nivel cognitivo de los niños no alcanzaba a comprender las nociones de conservación y seriación, es decir, hasta los siete años de edad en el nivel del pensamiento concreto.

Por otra parte, el equipo de Ginebra también ha comprobado que estructuras que sintácticamente violan el orden normal de la frase son generalmente mal comprendidas por los niños mientras no están en niveles cercanos al pensamiento operatorio concreto. Esto ha sido corroborado por Ferreiro (1971; citado por Clemente, 1995) con varios tipos de oraciones, especialmente las de carácter temporal y causal. En estas oraciones, si la estructura superficial intercambia el orden real de los sucesos, los niños tienden a comprenderlas mal puesto que, al parecer, su nivel cognitivo y lingüístico impide la disonancia que se produce entre el hecho real y su expresión lingüística formal, como sucede con la oración "antes de que el niño suba las escaleras, la niña lava el plato".

Otro aspecto que ha sido estudiado en relación con el desarrollo sintáctico en este último periodo es el de la transformación pasiva. Las oraciones pasivas 
adoptan como sujeto gramatical no al agente de la acción que se expresa a través del verbo, como es el caso de las oraciones activas, sino el paciente de esta acción. El agente de la acción expresada por el verbo o sujeto lógico sale a la superficie a través de una preposición denominada agentiva (normalmente por). La transformación pasiva también implica la intervención del auxiliar ser y del participio pasado ("Los niños son queridos por los padres"). En lo cognitivo, la coexistencia en el lenguaje de oraciones activas y pasivas correspondientes implica la capacidad de plantearse un mismo hecho desde un doble punto de vista, el de agente y el de paciente, y de codificar cada una de las alternativas de una manera formalmente distinta.

La producción de oraciones pasivas es estadísticamente débil, incluso en el lenguaje adulto. De acuerdo con Rondal (Puyuelo, Rondal \& Wiig, 2000), alrededor del 5 por ciento de las oraciones producidas por los adultos, como máximo, se formulan en voz pasiva. El niño no expresa oraciones pasivas antes de los siete u ocho años; aunque es capaz de comprender las pasivas no reversibles desde los cuatro o cinco años, hasta los nueve o diez años no se estabiliza la comprensión de las oraciones pasivas reversibles, ya que exigen un análisis sintáctico más profundo.

En una investigación realizada por Clemente (1995) sobre las oraciones pasivas, encontraron ejemplos de redundancia cuando se les pedía a los ni- ños inversiones de las frases (para formar pasivas). Por ejemplo, cuando se les pedía decir "la madre peina a la niña" empezando por la segunda palabra, pero con una oración que significara lo mismo, los niños entre cinco y ocho años, en lugar de hacer la correspondiente oración pasiva, tendían a redundar en oraciones como "la niña la que la madre la peina".

De acuerdo con este autor, se podría retomar la hipótesis defendida por Chomsky (1970) sobre las construcciones sintácticas difíciles para niños menores de cinco años:

1. Si el sujeto no es equivalente al sujeto gramatical.

2. Si el orden real de los sucesos no es el orden expresado en la oración.

3. Si no se respeta el principio de la mínima distancia. Por ejemplo, si el sujeto real de un verbo no es el sustantivo más cercano como sucede en la oración "María dijo a Pedro que recogería a los niños". Los niños creen que la persona más cercana al verbo (Pedro) es el sujeto de la oración (el que debe recoger a los niños).

Las adquisiciones gramaticales que ocurren más allá de los seis años no han sido muy estudiadas, debido a que se coincide en que en torno a los cinco años se consigue el dominio del sistema gramatical básico de una lengua y que, pasada esta edad, los logros más importantes hacen referencia a la consideración "multifuncional" de las di- 
ferentes categorías y estructuras gramaticales (Acosta et al., 1996).

No obstante, Rondal \& Crystal (citados por Acosta et al., 1996) completan la descripción anterior añadiendo algunos aspectos de adquisición más tardía, como son:

- Incremento en la producción de pronombres posesivos.

- Utilización correcta de adverbios y preposiciones de espacio y tiempo.

- Uso correcto de formas irregulares de los verbos.

- Aparición del pluscuamperfecto y condicional en el repertorio de producción de formas verbales.

- Uso de los determinantes como categorías gramaticales plurifuncionales.

- Aparición de las primeras oraciones del relativo, en sustitución de las yuxtapuestas y coordinadas.

- Uso adecuado de la concordancia de los tiempos verbales entre la oración principal y la subordinada.

\section{OBJetIVOS DE INVESTIGACIÓN}

\section{Objetivo general}

Estudiar la validez y confiabilidad del Módulo de Sintaxis de BLOC en niños de seis, siete y ocho años.

\section{Objetivos específicos}

- Desarrollar la adaptación lingüística del Módulo de Sintaxis de BLOC, a través del método de criterio de jueces, utilizando el coeficiente $\mathrm{V}$ de Aiken.

- Determinar la confiabilidad del Módulo de Sintaxis de BLOC, a través del método de la consistencia interna utilizando el coeficiente alpha de Cronbach.

- Determinar la validez de constructo del Módulo de Sintaxis de BLOC, utilizando el método intraprueba a través del análisis de los bloques, la matriz de correlaciones entre bloques y el análisis factorial.

- Determinar la validez concurrente del Módulo de Sintaxis de BLOC, a través del método de comparación de grupos.

- Elaborar baremos locales del Módulo de Sintaxis de BLOC para niños de seis, siete y ocho años.

\section{MÉTOdo}

\section{Participantes}

Los participantes seleccionados para la presente investigación son niños de seis, siete y ocho años pertenecientes a centros educativos regulares y de educación especializada ubicados en los distritos de Santiago de Surco, San Borja y Miraflores.

Los niños del grupo Sin dificultades de lenguaje fueron seleccionados de colegios parroquiales de dichos distritos en los que no se imparten cursos en inglés. 
Los criterios para seleccionar a los niños del grupo Con dificultades de lenguaje fueron:

1. Asistencia a colegios de educación especializada.

2. Diagnóstico neurológico, psicológico o de lenguaje y aprendizaje de retraso o dificultades en el lenguaje expresivo y/o comprensivo.

3. Nivel intelectual (CIG) dentro de los límites de la normalidad.

4. Se excluyó a aquellos niños que tuvieran algún otro diagnóstico que pudiera determinar las dificultades de lenguaje (autismo, retardo mental).

5. No se incluyó a niños que presentaron dificultades en el lenguaje exclusivamente de tipo articulatorio.

Los datos de este grupo de niños fueron extraídos de la historia personal del departamento psicopedagógico del colegio.

La tabla 1 presenta la distribución de los participantes estudiados, observándose que se contó con un total de
124 sujetos, 90 del grupo Sin dificultades de lenguaje y 34 del grupo Con dificultades de lenguaje.

En el caso del grupo Sin dificultades de lenguaje se contó con 30 niños pertenecientes a cada grupo de edad. Con respecto al grupo Con dificultades de lenguaje, estuvo conformado por nueve niños de seis años, 12 de siete años y 13 de ocho años.

El muestreo empleado fue de tipo no probabilístico, pues no se involucra ningún elemento aleatorio en la selección de la muestra. Específicamente, se trata de un muestreo intencional, ya que los sujetos participantes en la investigación fueron seleccionados deliberadamente por el investigador, de acuerdo con los criterios establecidos previamente.

\section{Instrumento}

El Módulo de Sintaxis de BLOC evalúa la capacidad del individuo para realizar una determinada estructura lingüística a partir de un enunciado.

Tabla 1

Distribución de los participantes según edad y diagnóstico

\begin{tabular}{lcccc}
\hline Diagnóstico & \multicolumn{3}{c}{ Edad } & Total \\
\hline Sin dificultades de lenguaje & 6 años & 7 años & 8 años & 30 \\
Con dificultades de lenguaje & 30 & 30 & 13 & 34 \\
Total & 9 & 12 & 43 & 124 \\
\hline
\end{tabular}


Se utiliza la producción paralela, en la que el alumno tiene que construir oraciones de la misma estructura que le presenta el entrevistador, basándose en el dibujo.

Está compuesto por 18 bloques, cada uno de los cuales consta de 10 ítems, siendo un total de 180 ítems. Los bloques que conforman el Módulo de Sintaxis son:

Bloque 1: Oraciones simples: sujetoverbo

Bloque 2: Oraciones simples: sujetoverbo-OD

Bloque 3: Oraciones simples: sujetoverbo - CCL

Bloque 4: Oraciones simples: sujetoverbo copulativo-atributo

Bloque 5: Oraciones simples: sujetoverbo-OD-CCL

Bloque 6: Oraciones simples: sujetoverbo-OD-OI

Bloque 7: Oraciones negativas

Bloque 8: Negación del atributo

Bloque 9: Pronombres y adverbios de negación

Bloque 10: Voz pasiva

Bloque 11: Sujetos coordinados. Objetos coordinados

Bloque 12: Verbos coordinados. Adjetivos coordinados

Bloque 13: Oraciones comparativas

Bloque 14: Oraciones subordinadas: causa y condición
Bloque 15: Subordinadas temporales: después / antes

Bloque 16: Subordinadas temporales: cuando / hasta que

Bloque 17: Subordinadas adversativas

Bloque 18: Subordinadas del relativo

Cada bloque explora determinada aptitud lingüística, según un modelo de dificultad creciente. Las instrucciones de aplicación se encuentran en el Manual de Imágenes y Administración del Módulo de Sintaxis (Puyuelo et al., 1998b). Las respuestas son anotadas en el Cuaderno de Registro.

\section{Procedimiento}

En primer lugar, se procedió a desarrollar la adaptación lingüística del Módulo de Sintaxis de BLOC. Para ello, se llevó a cabo una revisión detallada del contenido de los ítems, con el objetivo de determinar si el lenguaje utilizado se adecuaba al lenguaje estándar de nuestro medio. Se propusieron las modificaciones lingüísticas a los ítemes originales de la prueba, que fueron sometidas a criterio de jueces.

Se seleccionó un grupo de ocho jueces expertos en el campo del lenguaje, a quienes se les entregó una ficha con los ítemes originales y las modificaciones propuestas (ver apéndice 1), así como una copia del Manual de Imágenes y Administración del Módulo de Sinta- 
xis de BLOC, solicitándoles la aprobación o desaprobación de estas.

La segunda etapa de la investigación fue la recolección de los datos propiamente dicha. Se contactó los colegios con los criterios de inclusión previamente establecidos y tres colegios de educación especializada para niños con dificultades de lenguaje. La administración se realizó de manera individual y tomó un tiempo aproximado de una hora por cada niño.

La administración de la prueba a los niños estuvo a cargo de la investigadora. Las respuestas, así como los datos personales de cada niño, se registraron en el Cuaderno de Registro. En el caso del grupo de niños con dificultades de lenguaje, estos datos fueron extraídos de la historia personal del niño.

\section{Resultados}

\section{Adaptación lingüística}

El análisis de la aprobación/desaprobación de las modificaciones lingüísticas de los ítems del Módulo de Sintaxis de BLOC ha sido estudiada a través del método de criterio de jueces utilizando el coeficiente $\mathrm{V}$ de Aiken.

De acuerdo con Escurra (1988), en un grupo de ocho jueces se requiere que por lo menos siete estén en concordancia para que el ítem sea válido, alcanzando coeficiente $\mathrm{V}$ iguales o superiores a .88 , a un nivel de significación estadística de $\mathrm{p}<.05$. Las 45 modifi- caciones propuestas fueron aceptadas, ya que superan el criterio establecido.

\section{Estadísticos desciptivos}

En la tabla 2 se presentan los resultados del test de la bondad de ajuste a la curva normal de Kolmogorov-Smirnov de los puntajes de los bloques y del puntaje total del Módulo de Sintaxis de BLOC para el total de los sujetos estudiados (124).

El análisis de la bondad de ajuste a la curva normal da como resultado que el Módulo de Sintaxis presenta un coeficiente K-S Z que alcanza un nivel de probabilidad muy elevado, lo que indicaría que sus puntajes tienen una aceptable aproximación a la curva normal.

Sin embargo, en cuanto al análisis de normalidad por bloques, encontramos que en su mayoría no existe una adecuada semejanza a la curva normal, a excepción del bloque 7 Oraciones negativas y del bloque 9 Pronombres y adverbios de negación.

\section{Análisis de bloques y confiabilidad del módulo}

En la tabla 2 se presentan los resultados del análisis de los bloques del Módulo de Sintaxis de BLOC, con la media y la correlación ítem-test corregida, asumiéndose los puntajes de cada bloque como si fuera un ítem. Igualmente se presenta el coeficiente Kuder Richardson 20 y el coeficiente alpha de Cronbach como medida de confiabili- 
dad por consistencia interna de los bloques y del módulo, respectivamente.

En la tabla 3 podemos observar que los bloques que presentan mayor dificultad son los bloques $10 \mathrm{Voz}$ pasiva y el bloque 12 Verbos coordinados. Adjetivos coordinados, con una media de .81 y 1.15 , respectivamente. Los bloques más fáciles son el Bloque 4 Oraciones simples: sujeto-verbo copulativo-atributo $(\mathrm{M}=8.38)$, el Bloque 2 Oraciones simples: sujeto-verbo-OD

Tabla 2

Bondad de ajuste a la curva normal de Kolmogorov-Smirnov de los puntajes de los bloques y del puntaje total del Módulo de Sintaxis de BLOC para la muestra total

\begin{tabular}{|c|c|c|c|}
\hline Bloque & Media & D.E. & K-S Z \\
\hline B1 & 7.65 & 3.11 & $3.480^{\star * *}$ \\
\hline B2 & 8.08 & 1.71 & $2.215^{\star \star \star}$ \\
\hline B3 & 6.79 & 1.79 & $1.418^{*}$ \\
\hline B4 & 8.38 & 1.40 & $2.356^{\star * *}$ \\
\hline B5 & 7.16 & 1.40 & $1.916^{\star *}$ \\
\hline B6 & 5.98 & 1.70 & $1.696^{\star *}$ \\
\hline B7 & 5.98 & 3.00 & 1.216 \\
\hline B8 & 6.73 & 2.25 & $1.673^{\star *}$ \\
\hline B9 & 5.86 & 2.40 & 1.151 \\
\hline B10 & .81 & 1.91 & $4.888^{\star * *}$ \\
\hline B11 & 3.74 & 1.93 & $1.667^{* *}$ \\
\hline B12 & 1.15 & 1.65 & $2.872^{\star * *}$ \\
\hline B13 & 2.69 & 2.29 & $1.471^{*}$ \\
\hline B14 & 3.46 & 1.92 & $1.637^{\star *}$ \\
\hline B15 & 3.81 & 3.04 & $1.610^{*}$ \\
\hline B16 & 3.44 & 3.10 & $1.840^{* *}$ \\
\hline B17 & 6.09 & 3.11 & $1.465^{*}$ \\
\hline B18 & 3.69 & 1.59 & $2.667^{* * *}$ \\
\hline TOTAL & 91.49 & 20.39 & .937 \\
\hline
\end{tabular}

$(\mathrm{M}=8.08)$ y el Bloque 1 Oraciones simples: sujeto-verbo $(\mathrm{M}=7.65)$.

El criterio para aceptar o rechazar la correlación ítem-test corregida es que debe ser mayor o igual a 20 (Nunnaly \& Bernstein, 1995). Las correlaciones ítem-test oscilan entre .24 y .59 , observándose que todos los bloques obtienen correlaciones significativas con el puntaje total de módulo, siendo los bloques más discriminativos el Bloque 15 Subordinadas temporales: después/

Tabla 3

Índice de correlación ítem-test corregida del Módulo Sintaxis de BLOC

\begin{tabular}{|c|c|c|c|c|}
\hline Bloque & $M$ & ritc & KR20 & $\begin{array}{l}\text { Alpha si e } \\
\text { bloque es } \\
\text { eliminado }\end{array}$ \\
\hline B1 & 7.65 & $.24^{*}$ & .91 & .83 \\
\hline B2 & 8.08 & $.38^{*}$ & .57 & .82 \\
\hline B3 & 6.79 & $.38^{*}$ & .56 & .82 \\
\hline B4 & 8.38 & $.55^{\star}$ & .54 & .81 \\
\hline B5 & 7.16 & $.58^{\star}$ & .30 & .81 \\
\hline B6 & 5.98 & $.28^{*}$ & .53 & .82 \\
\hline B7 & 5.98 & $.37^{*}$ & .86 & .82 \\
\hline B8 & 6.73 & $.46^{*}$ & .76 & .81 \\
\hline B9 & 5.86 & $.25^{\star}$ & .70 & .82 \\
\hline B10 & .81 & $.35^{\star}$ & .89 & .82 \\
\hline B11 & 3.74 & $.32^{*}$ & .61 & .82 \\
\hline B12 & 1.15 & $.39^{*}$ & .71 & .82 \\
\hline B13 & 2.69 & $.58^{*}$ & .76 & .80 \\
\hline B14 & 3.46 & $.50^{*}$ & .74 & .81 \\
\hline B15 & 3.81 & $.59^{*}$ & .83 & .80 \\
\hline B16 & 3.44 & $.57^{*}$ & .86 & .80 \\
\hline B17 & 6.09 & $.54^{*}$ & .85 & .81 \\
\hline B18 & 3.69 & $.34^{*}$ & .68 & .82 \\
\hline
\end{tabular}


antes (.59), el Bloque 5 Oraciones simples: sujeto-verbo-OD-OI (.58), el Bloque 13 Oraciones comparativas (.58) y el Bloque 16 Subordinadas temporales: cuando/hasta que (.57).

El Alpha de Cronbach calculado para el Módulo alcanza un valor de .82 de manera que se puede decir que el Módulo Sintaxis del BLOC nos permite obtener puntajes confiables.

\section{Validez de constructo}

Las correlaciones obtenidas entre los bloques mediante el coeficiente de correlación producto-momento de Pearson muestran hasta qué punto las variaciones o cambios en un bloque corres- ponden a las variaciones o cambios en otro bloque. Dichas correlaciones se presentan en la tabla 4.

De las 153 correlaciones posibles entre los bloques encontramos 91 correlaciones estadísticamente significativas $(\mathrm{p}<.05)$, siendo todas ellas positivas. Las correlaciones estadísticamente significativas encontradas alcanzan coeficientes que oscilan entre .18 y .63 .

Existen cuatro correlaciones negativas no significativas entre los siguientes bloques: Bloque 1 Oraciones simples: sujeto-verbo y Bloque 6 Oraciones simples: sujeto-verbo-OD-OI ($.01)$; Bloque 6 Oraciones simples: sujeto-verbo-OD-OI y Bloque 11 Sujetos

Tabla 4

Matriz de correlaciones entre los bloques del Módulo Sintaxis de BLOC

\begin{tabular}{|c|c|c|c|c|c|c|c|c|c|c|c|c|c|c|c|c|c|}
\hline & B1 & B2 & B3 & B4 & B5 & B6 & B7 & B8 & B9 & B10 & B11 & B12 & B13 & B14 & B15 & B16 & B17 \\
\hline 32 & $.30^{* *}$ & & & & & & & & & & & & & & & & \\
\hline B3 & .08 & $.28^{\star *}$ & & & & & & & & & & & & & & & \\
\hline B4 & .14 & $.31^{* \star \star}$ & $.29^{\star *}$ & & & & & & & & & & & & & & \\
\hline B5 & $.28^{* *}$ & $.26^{* *}$ & $.33^{* * *}$ & $.40^{* * *}$ & & & & & & & & & & & & & \\
\hline B6 & -.01 & .17 & .11 & $.19^{*}$ & $.20^{*}$ & & & & & & & & & & & & \\
\hline B7 & .05 & $.22^{*}$ & $.23^{* *}$ & $.23^{* *}$ & .15 & .17 & & & & & & & & & & & \\
\hline B8 & .40 & $.21^{* *}$ & .11 & $.32^{* \star *}$ & $.21^{*}$ & $.21^{*}$ & $.63^{\star \star \star}$ & & & & & & & & & & \\
\hline B9 & .08 & .13 & .07 & .13 & $.30^{* *}$ & .08 & .13 & $.19^{*}$ & & & & & & & & & \\
\hline B10 & .12 & .13 & .10 & $.28^{* *}$ & .15 & .06 & .08 & .08 & .16 & & & & & & & & \\
\hline B11 & $.28^{* *}$ & $.30^{\star *}$ & .17 & $.27^{* *}$ & $.36^{* * *}$ & -.02 & .17 & $.24^{\star *}$ & .16 & .10 & & & & & & & \\
\hline B12 & .10 & .12 & $.18^{* *}$ & .16 & $.21^{*}$ & $.22^{*}$ & .09 & $.23^{*}$ & .17 & $.31^{\star \star \star}$ & .12 & & & & & & \\
\hline B13 & $.18^{*}$ & $.19^{*}$ & $.21^{* *}$ & $.40^{* * *}$ & $.41^{* * *}$ & .09 & $.23^{*}$ & $.30^{* *}$ & .16 & $.43^{\star \star \star}$ & .12 & $.30^{* *}$ & & & & & \\
\hline B14 & .11 & .08 & .10 & $.33^{* * *}$ & $.30^{* *}$ & .13 & .17 & $.27^{\star *}$ & $.31^{* * *}$ & $.18^{*}$ & .11 & $.31^{* * *}$ & $.36^{* * *}$ & & & & \\
\hline B15 & .15 & $.23^{* *}$ & $.38^{* * *}$ & $.42^{* * *}$ & $.40^{* * *}$ & $.22^{*}$ & $.18^{*}$ & $.20^{*}$ & .07 & $.26^{\star *}$ & $.22^{*}$ & $.34^{* \star *}$ & $.48^{\star * *}$ & $.44^{\star * *}$ & & & \\
\hline B16 & .14 & $.20^{*}$ & $.23^{*}$ & $.31^{* * *}$ & $.37^{* * *}$ & $.24^{* *}$ & $.19^{*}$ & $.27^{\star *}$ & .17 & $.36^{\star * *}$ & .15 & $.32^{* * *}$ & $.46^{* \star *}$ & $.42^{\star * *}$ & $.40^{* \star *}$ & & \\
\hline B17 & .16 & .14 & $.26^{* *}$ & $.33^{* * *}$ & $.34^{* \star *}$ & $.30^{* *}$ & $.26^{* *}$ & $.26^{* *}$ & -.003 & $.22^{*}$ & .10 & $.21^{*}$ & $.38^{\star * *}$ & $.40^{* * *}$ & $.51^{\star \star \star}$ & $.45^{\star * *}$ & \\
\hline B18 & .07 & .11 & $.20^{*}$ & $.33^{* * *}$ & $.36^{* \star *}$ & .09 & .13 & $.23^{*}$ & .13 & .03 & -.003 & .03 & $.30^{* *}$ & $.23^{*}$ & $.28^{* *}$ & $.23^{*}$ & $.27^{* *}$ \\
\hline
\end{tabular}

$\mathrm{N}=124$

${ }^{*} \mathrm{P}<.05 \quad{ }^{* *} \mathrm{p}<.01 \quad{ }^{* * *} \mathrm{p}<.001$ 
coordinados. Objetos coordinados (.02); Bloque 9 Pronombres y adverbios de negación y Bloque 17 Subordinadas adversativas (-.003); y entre el Bloque 11 Sujetos coordinados. Objetos coordinados y el Bloque 18 Subordinadas del relativo (-.003).

Se realizó el análisis factorial exploratorio a través del método de análisis de componentes principales. El método de extracción utilizado fue el mé- todo Oblimin y normalización con Kaiser.

Los resultados del análisis factorial exploratorio, presentados en la tabla 5, permiten observar que la medida de adecuación muestral de Kaiser-MeyerOlkin es de .81, alcanzándose un test de esfericidad de Barlett significativo, hallazgos que garantizan la pertinencia de los resultados de la ejecución del análisis factorial exploratorio. Se ob-

Tabla 5

Análisis factorial exploratorio del Módulo de Sintaxis de BLOC

\begin{tabular}{|c|c|c|c|c|c|}
\hline Bloque & Factor 1 & Factor 2 & Factor 3 & Factor 4 & Factor 5 \\
\hline B10 & .71 & & & & \\
\hline B12 & .70 & & & & \\
\hline B16 & .67 & & & & \\
\hline B13 & .64 & & & & \\
\hline B15 & .58 & & & & \\
\hline B14 & .57 & & & & \\
\hline B11 & & .73 & & & \\
\hline B2 & & .69 & & & \\
\hline B1 & & .65 & & & \\
\hline B8 & & & -.87 & & \\
\hline B7 & & & -.85 & & \\
\hline B6 & & & -.43 & & \\
\hline B9 & & & & .68 & \\
\hline B3 & & & & -.42 & \\
\hline B18 & & & & & -.79 \\
\hline B5 & & & & & -.65 \\
\hline B4 & & & & & -.56 \\
\hline B17 & & & & & -.54 \\
\hline Eigenvalue & 4.972 & 1.488 & 1.398 & 1.225 & 1.122 \\
\hline $\begin{array}{l}\% \text { de varianza } \\
\text { explicado }\end{array}$ & $27,60 \%$ & $8,27 \%$ & $7,80 \%$ & $6,78 \%$ & $6,26 \%$ \\
\hline
\end{tabular}

$\%$ de varianza acumulado $=56,70 \%$

Determinante: .0007484

Medida de adecuación muestral de Kaiser-Meyer-Oklin $=.81$

Prueba de esfericidad de Bartlett - Chi cuadrado aproximado $=568.63^{\star \star *}$

${ }^{* * *} p<.001 \quad \mathrm{~N}=124$ 
serva la existencia de cinco factores que permiten explicar el 56,7 por ciento de la varianza total.

Usando el criterio de Kaiser de autovalores mayores a 1.0 debería retenerse cinco factores. Sin embargo, algunos autores opinan que este método tiene como desventaja el sobredimensionamiento de la cantidad de factores por observar (Linn, 1968; Ruiz \& San Martín, 1992; Zwick \& Velicer, 1986; citados por Muñiz, 1996). Por ello, se aplicó el criterio propuesto por Horn (1965; citado por Muñiz, 1996) denominado "análisis paralelo", una adaptación de la regla de Kaisser, en el que se contrastan los autovalores encontrados empíricamente en los datos reales con los obtenidos a partir de una matriz de variables no correlacionadas basada en el mismo número de variables que los datos empíricos y en el mismo tamaño de muestra. Los componentes empíricos con autovalores superiores a los de la matriz aleatoria son retenidos.

De este modo, al efectuar el análisis paralelo se sugiere retener solo los factores con autovalores superiores a 1.7474. Siguiendo este criterio, encontramos que habría un solo factor dominante y que estadísticamente sería recomendable considerar, como se muestra en la tabla 6.

La tabla 7 muestra el resultado del análisis factorial confirmatorio del Módulo de Sintaxis de la Batería de Lenguaje Objetiva y Criterial, realizado a través del programa AMOS 4.0.
Tabla 6

Extracción de 1 factor del Módulo de Sintaxis de BLOC

\begin{tabular}{lrrc}
\hline Bloque & $\mathrm{M}$ & D.E. & Factor 1 \\
\hline B1 & 7.65 & 3.11 & .31 \\
B2 & 8.08 & 1.71 & .44 \\
B3 & 6.79 & 1.79 & .46 \\
B4 & 8.38 & 1.40 & .65 \\
B5 & 7.16 & 1.40 & .66 \\
B6 & 5.98 & 1.70 & .35 \\
B7 & 5.98 & 3.00 & .45 \\
B8 & 6.73 & 2.25 & .53 \\
B9 & 5.86 & 2.40 & .33 \\
B10 & .81 & 1.91 & .43 \\
B11 & 3.74 & 1.93 & .38 \\
B12 & 1.15 & 1.65 & .47 \\
B13 & 2.69 & 2.29 & .68 \\
B14 & 3.46 & 1.92 & .59 \\
B15 & 3.81 & 3.04 & .70 \\
B16 & 3.44 & 3.10 & .66 \\
B17 & 6.09 & 3.11 & .64 \\
B18 & 3.69 & 1.59 & .44 \\
\hline
\end{tabular}

$\%$ de varianza explicado $=27,60 \%$

Medida de adecuación muestral de KaiserMeyer-Oklin $=.81$

Prueba de esfericidad de Bartlett - Chi cuadrado aproximado $=568.64^{\star \star *}$

*** $p<.001$

$\mathrm{N}=124$

El análisis estadístico del modelo propuesto en comparación con el modelo saturado (todas las variables están relacionadas entre sí) y el modelo independiente (todas las variables son independientes entre sí) refleja que el primero es más eficiente, pues obtiene un chi-cuadrado menor $\left(X^{2}=136.44, \mathrm{gl}=\right.$ $113, \mathrm{p}<.05$ ), así como una menor proporción entre chi-cuadrado y grado de libertad $\left(X^{2} / \mathrm{gl}=1.12\right)$. También se aprecia que el índice de bondad de 
Tabla 7

Análisis factorial confirmatorio del modelo de 1 factor del Módulo de Sintaxis de BLOC

\begin{tabular}{lccc}
\hline Estadístico & Modelo Propuesto & Modelo Saturado & Modelo Independiente \\
\hline $\mathrm{X}^{2}$ & 136.44 & 0.00 & 602.08 \\
$\mathrm{gl}$ & 113 & 0 & 153 \\
$\mathrm{P}$ & .066 & & 0.000 \\
$\mathrm{X}^{2} / \mathrm{gl}$ & 1.21 & & 3.94 \\
Número de parámetros & 58 & 171 & 18 \\
$\mathrm{GFI}$ & 0.90 & 1.00 & 0.49 \\
$\mathrm{AGFI}$ & 0.85 & & 0.43 \\
Residuo medio Cuadrado (RMR) & 0.28 & 0.000 & 1.25 \\
Residuo medio Cuadrado & & & 0.15 \\
estandarizado (RMSEA) & 0.04 & &
\end{tabular}

$\mathrm{N}=124$

ajuste (GFI) alcanza un valor adecuado (.90), así como un índice de bondad de ajuste corregido (AGFI) que también es aceptable (.85).

Estos resultados nos indican que el modelo propuesto de un factor es adecuado a la estructura de los datos.

\section{Análisis comparativo}

La tabla 8 presenta los resultados del análisis de varianza de un factor para la comparación de medias en el Módulo de Sintaxis por Edad (seis, siete y ocho años).

Al establecer la comparación por edad observamos que hay diferencias significativas en el puntaje total del Módulo de Sintaxis de BLOC entre los tres grupos estudiados $(\mathrm{F}=12.31 ; \mathrm{p}<.001)$. El análisis a posteriori realizado a través del test de Sheffe indica que los niños de ocho años ( $\mathrm{M}=101.84)$ alcanzan un desempeño significativamente mejor que los niños de siete años $(\mathrm{M}=90.29)$ y que los de seis años $(\mathrm{M}=81.38)$.

Tabla 8

Análisis de varianza de un factor para comparación de medias en el Módulo de Sintaxis por edad

\begin{tabular}{cccc}
\hline \multicolumn{3}{c}{ Edad } & $\mathrm{F}$ \\
\hline 6 años & 7 años & 8 años & \\
$(\mathrm{N}=39)$ & $(\mathrm{N}=42)$ & $(\mathrm{N}=43)$ & \\
$81.38 \mathrm{a}$ & $90.29 \mathrm{~b}$ & $101.84 \mathrm{ab}$ & $12.31^{* * *}$ \\
\hline
\end{tabular}

${ }^{\star * *} \mathrm{p}<.001$

Diferencias significativas a través del Test de Sheffe: $a, b$ 
Tabla 9

Prueba de Kruskal-Wallis para comparación de los puntajes en los bloques del Módulo de Sintaxis por Edad

\begin{tabular}{lcccc}
\hline & \multicolumn{3}{c}{ MR } & \\
\cline { 2 - 4 } Bloque & 6 años & 7 años & 8 años & \multirow{2}{*}{$X^{2}$} \\
& $(\mathrm{~N}=39)$ & $(\mathrm{N}=42)$ & 68.73 & 4.66 \\
\hline B1 & 52.86 & 65.07 & 71.63 & 5.79 \\
B2 & 52.95 & 62.02 & 67.67 & 1.41 \\
B3 & 59.32 & 60.15 & $70.81 \mathrm{a}$ & $8.72^{*}$ \\
B4 & $49.14 \mathrm{a}$ & 66.39 & 71.95 & 4.82 \\
B5 & 59.88 & 58.04 & 68.14 & 1.68 \\
B6 & 59.18 & 59.81 & 67.00 & 2.12 \\
B7 & 55.86 & 64.06 & $74.84 \mathrm{a}, \mathrm{b}$ & $8.10^{*}$ \\
B8 & $54.24 \mathrm{a}$ & $57.54 \mathrm{~b}$ & $73.08 \mathrm{a}, \mathrm{b}$ & $6.05^{*}$ \\
B9 & $58.94 \mathrm{a}$ & $54.98 \mathrm{~b}$ & 69.64 & 5.15 \\
B10 & 57.04 & 60.26 & 69.03 & 5.60 \\
B11 & 51.55 & 65.98 & $77.24 \mathrm{a}, \mathrm{b}$ & $13.12^{* * *}$ \\
B12 & $52.63 \mathrm{a}$ & $56.57 \mathrm{~b}$ & $79.77 \mathrm{a}, \mathrm{b}$ & $15.72^{* * *}$ \\
B13 & $52.03 \mathrm{a}$ & $54.55 \mathrm{~b}$ & $70.51 \mathrm{a}, \mathrm{b}$ & $6.61^{*}$ \\
B14 & $50.95 \mathrm{a}$ & $65.02 \mathrm{~b}$ & $73.23 \mathrm{a}, \mathrm{b}$ & $10.36^{* *}$ \\
B15 & $48.23 \mathrm{a}, \mathrm{b}$ & $64.76 \mathrm{~b}$ & $72.84 \mathrm{a}, \mathrm{b}$ & $6.13^{*}$ \\
B16 & $54.13 \mathrm{a}$ & $59.69 \mathrm{~b}$ & $73.31 \mathrm{a}$ & $6.24^{*}$ \\
B17 & $55.45 \mathrm{a}$ & 57.98 & 66.37 & .90 \\
B18 & 59.54 & 61.29 & & \\
\hline
\end{tabular}

${ }^{*} p<.05^{* *} p<.01^{* * *} p<.001$

$\mathrm{gl}=2$

Diferencias significativas a través de la Prueba de Mann-Whitney: $a, b$

En la tabla 9 se presentan los resultados de la prueba de Kruskal-Wallis para comparación de los puntajes en los bloques del Módulo de Sintaxis por Edad (seis, siete y ocho años). Podemos observar que al establecer la comparación de los puntajes alcanzados en los bloques del Módulo Sintaxis de acuerdo con la edad, existen diferencias significativas en nueve de los 18 bloques del módulo, observándose además que en todos los casos el menor valor corresponde al grupo de seis años y el valor mayor al grupo de ocho años.
Adicionalmente, los resultados de la prueba de Mann-Whitney nos indican entre qué edades se encuentran estas diferencias. Así, observamos que entre los niños de seis y siete años solo presentan diferencias estadísticamente significativas en el Bloque 15 Subordinadas temporales: después / antes $\left(\mathrm{X}^{2}=10.36 ; \mathrm{p}<.01\right)$.

Por otra parte, entre los niños de seis y ocho años encontramos diferencias significativas en el Bloque 4 Oraciones simples: sujeto-verbo copulativo-atributo $\left(\mathrm{X}^{2}=8.72 ; \mathrm{p}<.05\right)$, 
Bloque 8 Negación del atributo $\left(\mathrm{X}^{2}=\right.$ $8.10 ; \mathrm{p}<.05)$, Bloque 9 Pronombres $y$ adverbio de negación $\left(\mathrm{X}^{2}=6.05 ; \mathrm{p}<\right.$ $.05)$, Bloque 12 Verbos coordinados/adjetivos coordinados $\left(\mathrm{X}^{2}=13.12\right.$; $\mathrm{p}<.001)$, Bloque 13 Oraciones comparativas $\left(\mathrm{X}^{2}=15.72 ; \mathrm{p}<.001\right)$, Bloque 14 Oraciones subordinadas: causa $y$ condición $\left(\mathrm{X}^{2}=6.61 ; \mathrm{p}<.05\right)$, Bloque 15 Subordinadas temporales: después / antes $\left(\mathrm{X}^{2}=10.36 ; \mathrm{p}<.01\right)$, Bloque 16 Subordinadas temporales: cuando/ hasta que $\left(\mathrm{X}^{2}=6.13 ; \mathrm{p}<.05\right)$ y Bloque 17 Subordinadas adversativas $\left(\mathrm{X}^{2}=6.24 ; \mathrm{p}<.05\right)$. parativas $\left(\mathrm{X}^{2}=15.72 ; \mathrm{p}<.001\right) \mathrm{y}$ Bloque 16 Subordinadas temporales: cuando/hasta que $\left(\mathrm{X}^{2}=6.13 ; \mathrm{p}<.05\right)$.

En la tabla 10 se presentan los resultados de la prueba $t$ de comparación de medias de acuerdo con el diagnóstico (con y sin dificultades de lenguaje) en el puntaje total del Módulo de Sintaxis.

En ella encontramos que existen diferencias significativas $(\mathrm{T}=3.05$; $\mathrm{p}<.01)$ entre ambos grupos estudiados, observando que los niños sin dificultades de lenguaje obtienen una media de 94.81 y una desviación estándar de 19.23 en el puntaje total del

Tabla 10

Prueba t de comparación de medias del grupo con dificultades y sin dificultades de lenguaje en el puntaje total del Módulo de Sintaxis

\begin{tabular}{ccccc}
\hline \multicolumn{2}{c}{$\begin{array}{c}\text { Sin dificultades } \\
(\mathrm{N}=90)\end{array}$} & \multicolumn{2}{c}{$\begin{array}{c}\text { Con dificultades } \\
(\mathrm{N}=34)\end{array}$} & $\mathrm{T}$ \\
\hline $\mathrm{M}$ & $\mathrm{DE}$ & $\mathrm{M}$ & $\mathrm{DE}$ & \\
94.81 & 19.23 & 82.70 & 21.04 & $3.05^{\star *}$ \\
\hline
\end{tabular}

Se encuentran también diferencias significativas entre los niños de siete y ocho años entre los siguientes bloques: Bloque 8 Negación del atributo $\left(\mathrm{X}^{2}=\right.$ $8.10 ; \mathrm{p}<.05)$, Bloque 9 Pronombres $y$ adverbio de negación $\left(\mathrm{X}^{2}=6.05 ; \mathrm{p}<\right.$ $.05)$, Bloque 12 Verbos coordinados ladjetivos coordinados $\left(\mathrm{X}^{2}=13.12\right.$; $\mathrm{p}<.001$ ), Bloque 13 Oraciones com-
Módulo de Sintaxis, mientras los niños con dificultades de lenguaje tienen un puntaje total promedio de 82.20 y una desviación estándar de 21.04.

Estos datos nos indicarían que el Módulo de Sintaxis de BLOC permite establecer diferencias estadísticamente significativas entre los niños con y sin dificultades de lenguaje. 
La tabla 11 presenta los resultados de la prueba de Mann-Whitney de comparación de medias de acuerdo con el diagnóstico (sin dificultades y con dificultades de lenguaje) en los puntajes alcanzados en los bloques del Módulo de Sintaxis.

Podemos observar que, al hacer la comparación de medias de acuerdo con el diagnóstico en los puntajes por bloque, encontramos diferencias significativas entre los grupos con dificultades y sin dificultades de lenguaje en los siguientes bloques: Bloque 3 Oraciones simples: sujeto-verbo-complemento circunstancial de lugar, Bloque 4 Oraciones simples: sujeto-verbo copulativoatributo, Bloque 5 Oraciones simples: sujeto-verbo-objeto directo-complemento circunstancial de lugar, Bloque 6 Oraciones simples: sujeto-verbo-objeto directo-objeto indirecto, Bloque $12 \mathrm{Ver}$ bos coordinados/adjetivos coordinados, Bloque 13 Oraciones comparativas, Bloque 14 Oraciones subordinadas: Causa y condición, y Bloque 15 Subordinadas temporales: después/antes que. En todos los casos el grupo sin dificul-

Tabla 11

Prueba de Mann-Whitney de comparación de medias del grupo sin dificultades y con dificultades en los puntajes de los bloques del Módulo de Sintaxis

\begin{tabular}{lcccccc}
\hline Bloque & \multicolumn{2}{c}{$\begin{array}{c}\text { Sin dificultades } \\
(\mathrm{N}=90)\end{array}$} & \multicolumn{2}{c}{$\begin{array}{c}\text { Con dificultades } \\
(\mathrm{N}=34)\end{array}$} & $\mathrm{U}$ & $\mathrm{Z}$ \\
\cline { 2 - 5 } & $\mathrm{RP}$ & $\mathrm{SR}$ & $\mathrm{RP}$ & $\mathrm{SR}$ & & \\
\hline B1 & 64.87 & 5838.50 & 56.22 & 1911.50 & 1316.50 & -1.24 \\
B2 & 64.98 & 5848.0 & 55.94 & 1902.00 & 1307.00 & -1.28 \\
B3 & 67.84 & 6105.50 & 48.37 & 1644.50 & 1049.50 & $-2.73^{\text {** }}$ \\
B4 & 67.64 & 6087.50 & 48.90 & 1662.50 & 1067.50 & $-2.68^{* *}$ \\
B5 & 70.13 & 6312.00 & 42.29 & 1438.00 & 843.00 & $-3.95^{* * *}$ \\
B6 & 66.88 & 6019.00 & 50.91 & 1731.00 & 1136.00 & $-2.24^{*}$ \\
B7 & 60.97 & 5487.00 & 66.56 & 2263.00 & 1392.00 & -.78 \\
B8 & 61.03 & 5492.50 & 66.40 & 2257.50 & 1397.50 & -.75 \\
B9 & 62.22 & 5600.00 & 63.24 & 2150.00 & 1505.00 & -.14 \\
B10 & 64.35 & 5791.50 & 57.60 & 1958.50 & 1363.50 & -.1 .27 \\
B11 & 59.76 & 5378.00 & 69.76 & 2372.00 & 1283.00 & -1.40 \\
B12 & 64.28 & 5785.50 & 57.78 & 1964.50 & 1369.50 & -.97 \\
B13 & 67.60 & 6084.00 & 49.00 & 1666.00 & 1071.00 & $-2.61^{* *}$ \\
B14 & 68.72 & 6185.00 & 46.03 & 1565.00 & 970.00 & $-3.20^{* * *}$ \\
B15 & 66.99 & 6029.00 & 50.62 & 1721.00 & 1126.00 & $-2.29^{*}$ \\
B16 & 66.32 & 5969.00 & 52.38 & 1781.00 & 1186.00 & $-1.96^{*}$ \\
B17 & 70.04 & 6306.50 & 42.54 & 1446.50 & 851.50 & $-3.86^{* * *}$ \\
B18 & 65.47 & 5892.00 & 54.65 & 1858.00 & 1263.00 & -1.58 \\
\hline
\end{tabular}

${ }^{*} p<.05 \quad{ }^{* *} p<.01 \quad{ }^{* * *} p<.001$ 
tades de lenguaje alcanza un mejor desempeño (mayor rango promedio) que el grupo con dificultades de lenguaje.

\section{Elaboración de baremos}

En el apéndice 2 se presentan las tablas con los baremos elaborados mediante el método de percentiles.

La tabla 12 corresponde a los baremos normativos en percentiles (Pc) para la conversión de puntajes directos (PD) por grupo de edad (6, 7 y 8 años) para la puntuación total obtenida en el Módulo de Sintaxis de la Batería de Lenguaje Objetiva y Criterial (BLOC).

En las tablas 13 a 15 se presentan los baremos normativos por grupo de edad (seis, siete y ocho años, respectivamente) para la conversión de los puntajes directos (PD) a percentiles (Pc) a partir de la puntuación obtenida en cada uno de los bloques del Módulo de Sintaxis de la Batería de Lenguaje Objetiva y Criterial (BLOC)

\section{DISCUSIÓN}

De acuerdo con los objetivos de investigación, se analizó la validez y confiabilidad de la adaptación lingüística del Módulo de Sintaxis de BLOC para determinar si funcionaba de forma apropiada en un grupo de niños limeños de seis, siete y ocho años. Los resultados encontrados en el análisis psicométrico aportan evidencia a favor de que la adaptación lingüística del Módulo de Sintaxis BLOC obtiene niveles de vali- dez y confiabilidad aceptables, a partir de lo cual se puede concluir que la prueba puede funcionar en nuestro medio y es consistente con la versión española.

Lo anterior es confirmado, en primer lugar, con los resultados obtenidos en el análisis psicométrico de la prueba a través del cual encontramos que todos los bloques obtienen correlaciones significativas con el módulo. Así los 18 bloques son aceptados y concordantes entre sí, lo cual demuestra que la adaptación lingüística del Módulo de Sintaxis de BLOC es consistente con la versión española.

En segundo lugar, para calcular la confiabilidad del Módulo de Sintaxis de BLOC se evaluó la consistencia interna mediante el coeficiente alpha de Cronbach, observándose que el valor alcanzado fue estadísticamente significativo (.82), lo cual evidencia que el Módulo de Sintaxis de BLOC nos permite obtener puntajes confiables.

Con relación a los resultados encontrados en los bloques que conforman el Módulo de Sintaxis de BLOC, tenemos que los coeficientes de confiabilidad, calculados mediante la fórmula KuderRichardson 20, fluctuaron en un rango que va de .30 para el Bloque 5 Oraciones simples: sujeto-verbo-OD-OI y .91 para el Bloque 1 Oraciones simples: sujeto-verbo.

De los 18 bloques que constituyen el Módulo de Sintaxis de BLOC, 13 
obtuvieron coeficientes de confiabilidad aceptables, con valores entre $.61 \mathrm{y}$ .91. Por otra parte, encontramos que 5 bloques presentan bajos coeficientes de confiabilidad, entre .30 y .57. Por lo general, los bloques que no alcanzan coeficientes de confiabilidad aceptables son bloques conformados por ítems que no alcanzan niveles significativos de correlación ítem-test. Sin embargo, se observa también que los bajos niveles de correlación que demuestran estos ítems pueden ser explicados por el nivel de dificultad, es decir que son ítems muy fáciles o muy difíciles. Al respecto, Nunnally \& Bernstein (1995) subrayan que los valores correlación reactivo-total corregido están sesgados hacia reactivos con valores $p$ (índice de dificultad) intermedios. Tener reactivos de dificultades variadas puede causar un sacrificio marginal en el coeficiente de consistencia interna; sin embargo, aumentará la capacidad de la prueba para discriminar a todos los niveles.

Para obtener datos con respecto a la validez de constructo del Módulo de Sintaxis de BLOC se calculó la Matriz de Correlaciones entre los bloques y posteriormente se empleó el análisis factorial.

Al analizar la matriz de correlaciones, encontramos correlaciones significativas entre la mayor parte de los bloques del módulo, es decir, entre las diferentes áreas o competencias que explora la prueba.
Se observa, de igual modo, que las correlaciones más altas se dan principalmente entre los bloques que evalúan oraciones negativas, construcciones con estructuras sintácticas más complejas (comparativas, subordinadas, pasivas) o en aquellas de mayor longitud, es decir, aquellas oraciones en las que se incluye más de un complemento (objeto directo y circunstancial de lugar).

A continuación se realizó el análisis factorial exploratorio, a través del método de análisis de componentes principales tomando el criterio de las raíces latentes (autovalores) superiores a 1.00. Los resultados de dicho análisis reportaron inicialmente la existencia de cinco factores que explicarían el 56,7 por ciento de la varianza. Al analizar dichos factores, encontramos una diferencia sustancial entre el porcentaje de varianza explicado por el primer factor frente a los cuatro restantes. Esto sería un primer indicio de la existencia de un factor dominante.

Uno de los principales problemas del análisis factorial es determinar el criterio que se debe tener en cuenta para el número de factores por retener en la explicación de la dimensionalidad subyacente a un conjunto de datos. Se optó en este caso por utilizar el criterio propuesto por Horn (1965; citado por Muñiz, 1996). De este modo, al efectuar el análisis paralelo se sugiere retener solo los factores con autovalores superiores a 1.7474, encontrando que en el Módulo de Sintaxis de BLOC habría un 
solo factor dominante y que sería estadísticamente recomendable considerar.

Para corroborar la adecuación del modelo de un factor a la estructura de los datos, se realizó el análisis factorial confirmatorio, encontrando que los resultados obtenidos en dicho análisis apoyan la aceptación de este modelo.

De este modo, se puede concluir que los resultados encontrados a través del análisis factorial apuntan hacia la homogeneidad de la medida o unidimensionalidad, lo cual aporta evidencia a favor de la validez de constructo del Módulo de Sintaxis de BLOC. Esto quiere decir que, de acuerdo con la propuesta de los autores, este módulo evalúa la competencia lingüística en el componente sintáctico.

Con el objetivo de evaluar la validez concurrente del Módulo de Sintaxis de BLOC se utilizó el método de comparación de grupos contrastantes, para determinar si existen diferencias significativas en los puntajes alcanzados, de acuerdo con la edad así como en el rendimiento de los niños con diagnóstico de dificultades de lenguaje frente a los que no lo tienen.

Se efectuó la comparación por edad, considerado como indicador de desarrollo lingüístico, ya que las puntuaciones deben ir aumentando progresivamente con la edad de los examinados. Los datos mostraron una fuerte sensibilidad del Módulo de Sintaxis ante esta variable, encontrándose que existen diferencias significativas entre los tres grupos estudiados tanto a nivel del módulo como en algunos de los bloques.

Con respecto al puntaje total alcanzado en el Módulo de Sintaxis de BLOC, se observa un desempeño significativamente superior en los niños de ocho años respecto a los de siete y seis años. No se encuentran, sin embargo, diferencias estadísticamente significativas entre los niños de seis y siete años.

Una posible explicación de esos resultados se puede hacer tomando como punto de referencia la teoría de desarrollo cognitivo de Piaget, quien plantea que a los siete años se da el paso del pensamiento preoperatorio a las operaciones concretas. Así, las diferencias entre los puntajes obtenidos por los niños de seis y siete años en comparación con los de ocho años en el Módulo de Sintaxis de BLOC se explicarían también situando los siete años como un periodo de transición en el desarrollo del lenguaje, en este caso específico, en el desarrollo de las estructuras sintácticas relacionado con la adquisición de las operaciones lógicas de clasificación, conservación y seriación. De igual modo, estos resultados apoyan la propuesta de Sinclair (1967; citado por Acosta et al., 1996) acerca de la dependencia de ciertas estructuras del lenguaje en relación con el nivel de desarrollo operatorio alcanzado.

Al analizar los puntajes alcanzados en los bloques del Módulo de Sintaxis 
de BLOC se observa consistentemente un mejor rendimiento en los niños de ocho años respecto a los de siete, y de estos respecto a los de seis años. Igualmente, encontramos que en nueve de los 18 bloques que conforman el módulo existen diferencias significativas de acuerdo a la edad.

Como en el caso del puntaje total del módulo, las diferencias encontradas se dan entre los niños de seis y siete años frente a los de ocho años. Estas diferencias se presentan principalmente en los bloques que evalúan la capacidad del niño para realizar oraciones con estructuras sintácticas más complejas. Así, observamos que las diferencias con mayor nivel de significación se dan en los bloques que evalúan la coordinación de verbos y adjetivos, oraciones comparativas y subordinadas temporales.

En el caso de las oraciones coordinadas, las diferencias encontradas pueden explicarse, más que en términos de la complejidad de la estructura sintáctica, en relación con la mayor longitud del enunciado solicitado, el cual representa, a su vez, una mayor carga para la memoria a corto plazo.

Con respecto a las oraciones comparativas, las diferencias encontradas de acuerdo con la edad se explican dado que el uso de los términos relacionales requiere la comprensión de las nociones de conservación y seriación en la etapa del pensamiento lógicoconcreto (Sinclair, 1967; citado por Clemente, 1995).
Igualmente, la comprensión y uso de las oraciones subordinadas casuales y temporales, requiere también que el niño se encuentre en el nivel de pensamiento operatorio, tal como lo explica Ferreiro (1971; citado por Clemente, 1995).

Las diferencias encontradas en relación con la edad son consistentes con los resultados encontrados en la versión original de BLOC en la que se reporta una correlación de .83 entre los puntajes obtenidos en el Módulo de Sintaxis y la variable edad (Renom, Solanas \& Puyuelo, 1995). De este modo, podemos afirmar que el Módulo de Sintaxis de BLOC es sensible para evaluar el desarrollo sintáctico estableciendo diferencias de acuerdo al nivel de dominio alcanzado por los niños de diferentes edades.

En cuanto a la comparación de acuerdo con el diagnóstico de dificultades de lenguaje, encontramos diferencias significativas entre los grupos estudiados en el puntaje total alcanzado en el Módulo de Sintaxis de BLOC. Del mismo modo, se observan diferencias significativas entre los grupos con y $\sin$ dificultades de lenguaje, todas ellas a favor del grupo sin dificultades, en nueve de los 18 bloques del módulo.

Las principales diferencias encontradas entre ambos grupos se dan en el uso de los complementos (complemento circunstancial de lugar, objeto directo e indirecto), en la coordinación de verbos y adjetivos, en las oraciones 
comparativas y en las subordinadas causales y temporales. Al respecto, Smiley \& Goldstein (1998; citado por Acosta \& Moreno, 1999) señalan que los principales problemas que presentan los niños con dificultades en el componente sintáctico del lenguaje afectan las construcciones que llevan consigo adiciones, supresiones y redisposiciones de elementos, como es el caso de las oraciones negativas, imperativas, pasivas, interrogativas, $y$, especialmente, en las oraciones coordinadas y subordinadas.

De este modo, se puede concluir que el Módulo de Sintaxis de BLOC permite discriminar entre los niños con y sin dificultades de lenguaje. En este sentido, la prueba cumple con uno de los principales objetivos de la evaluación, es decir, determinar si el niño presenta algún tipo de alteración o retraso en el lenguaje (Puyuelo, Rondal \& Wiig, 2000).

\section{REFERENCIAS}

Acosta, V. \& Moreno, A. (1999). Dificultades del lenguaje en ambientes educativos: Del retraso al trastorno especifico del lenguaje. Barcelona: Masson.

Acosta, V. et al., (1996). La evaluación del lenguaje: Teoría y práctica del proceso de evaluación infantil. Málaga: Ediciones Alijibe.

Bloom, L. \& Lahey, M. (1978). Language development and language disorders. New York: John Wiley And Sons.
Chomsky, N. (1970). Aspectos de la teoría de la sintaxis. Madrid: Aguilar.

Clemente, R. (1995). Desarrollo del lenguaje: Manual para profesionales de la intervención en ambientes educativos. Barcelona: Octaedro.

Escurra, L. M. (1988). Cuantificación de la validez de contenido por el criterio de jueces. Revista de Psicología, 6, 103111.

Fernández, M. \& Anula, A. (1995). Sintaxis y cognición. Madrid: Editorial Síntesis.

Fernández, W. (1990). Curso completo de lengua española. Lima: Editorial San Marcos.

Inurritegui, S. (2004). Adaptación psicométrica y elaboración de baremos del Módulo de Sintaxis de la Batería de Lenguaje Objetiva y Criterial. Tesis para optar el título de licenciada en psicología. Lima: Universidad de Lima, Facultad de Psicología.

Martínez Celdrán, E. (1998). Lingüistica: Teoría y aplicaciones. Barcelona: Masson.

Matos, L. (1998). Análisis de la validez de la prueba Illinois de habilidades psicolingüísticas (ITPA). Tesis para optar el título de licenciada en psicología. Lima: Universidad de Lima, Facultad de Psicología.

Muñiz, J. (1996). Psicometría. Madrid: Universitas.

Nunnally, J. \& Bernstein, I. (1995). Teoría psicométrica. México DF: MacGrawHill.

Piaget, J. (1961). La formación del símbolo en el niño. México DF: Fondo de Cultura Económica. 
Puyuelo, M.; Rondal, J. \& Wiig, E. (2000). Evaluación del lenguaje. Barcelona: Masson.

Puyuelo, M. (1995). Revisión sobre los procedimientos de evaluación del lenguaje. Historia y actualidad de los métodos de evaluación. Revista de Logopedia, Foniatrìa y Audiologìa, 15(2), 76-93.

Puyuelo, M. et al., (1998a). Batería de Lenguaje Objetiva y Criterial (BLOC). Manual de evaluación. Barcelona: Masson.
Puyuelo, M. et al., (1998b). Batería de Lenguaje Objetiva y Criterial (BLOC). Manual de imágenes y administración: Sintaxis. Barcelona: Masson.

Renom, J., Solanas, A. \& Puyuelo, M. (1995). Análisis psicométrico de una prueba de lenguaje y su adaptación informática. Revista de Logopedia, Foniatría y Audiología, 15(2), 121-137.

Triadó, C. \& Forns, M. (1989). La evaluación del lenguaje: una aproximación evolutiva. Barcelona: Paidós. 


\section{APÉNDICE 1}

\section{Batería de Lenguaje Objetiva y Criterial: Módulo de Sintaxis Modificación de ítems}

\begin{tabular}{|c|c|c|c|}
\hline \multicolumn{2}{|c|}{ Bloque Ítem } & \multirow{2}{*}{$\begin{array}{l}\text { Pág. } \\
15\end{array}$} & Modificación \\
\hline 2 & Demo & & $\begin{array}{l}\text { INTRODUCCIÓN: Mira mi dibujo (señalarlo). Te voy a explicar algo de él. El } \\
\text { chico toma leche. }\end{array}$ \\
\hline & & & PRUEBA: Ahora mira tu dibujo. Explícamelo (la chica come un helado). \\
\hline \multirow[t]{2}{*}{2} & 4 & 17 & INTRODUCCIÓN: El chico pinta una banca. \\
\hline & & & PRUEBA: Explícame tu dibujo (la chica corta un árbol). \\
\hline \multirow[t]{2}{*}{2} & 8 & 21 & INTRODUCCIÓN: Las chicas plantan papas. \\
\hline & & & Prueba: Explícame el tuyo (los niños cogen flores). \\
\hline \multirow[t]{2}{*}{2} & 10 & 21 & INTRODUCCIÓN: Los policías paran el tráfico. \\
\hline & & & $\begin{array}{l}\text { PRUEBA: Explícame el tuyo (los bomberos lavan el camión / el carro de bom- } \\
\text { beros). }\end{array}$ \\
\hline \multirow[t]{2}{*}{3} & 6 & 29 & INTRODUCCIÓN: Mira este dibujo. \\
\hline & & & PRUEBA: Dime dónde juegan los niños (los niños juegan en la vereda). \\
\hline \multirow[t]{2}{*}{3} & 7 & 29 & INTRODUCCIÓN: Mira este dibujo. \\
\hline & & & $\begin{array}{l}\text { PRUEBA: Dime dónde están sentados los niños (los niños están sentados en } \\
\text { sus carpetas). }\end{array}$ \\
\hline \multirow[t]{2}{*}{3} & 10 & 31 & INTRODUCCIÓN: Mira este dibujo. \\
\hline & & & $\begin{array}{l}\text { PRUEBA: Dime algo acerca de los niños (los niños toman agua de la man- } \\
\text { guera). }\end{array}$ \\
\hline \multirow[t]{2}{*}{4} & 2 & 37 & INTRODUCCIÓN: El tazón está vacío. \\
\hline & & & PRUEBA: Dime algo del vaso (el vaso está lleno). \\
\hline \multirow[t]{2}{*}{4} & 6 & 39 & INTRODUCCIÓN: Los pantalones están sucios. \\
\hline & & & PRUEBA: Ahora dime algo de las botas del dibujo (las botas están limpias). \\
\hline \multirow[t]{2}{*}{4} & 9 & 41 & INTRODUCCIÓN: Los carros son rápidos. \\
\hline & & & PRUEBA: Ahora dime algo de las tortugas (las tortugas son lentas) \\
\hline \multirow[t]{2}{*}{4} & 10 & 41 & INTRODUCCIÓN: La cinta es angosta. \\
\hline & & & PRUEBA: Dime algo del cinturón de este dibujo (el cinturón es ancho). \\
\hline \multirow[t]{2}{*}{5} & 1 & 45 & INTRODUCCIÓN: Mira este dibujo. \\
\hline & & & $\begin{array}{l}\text { PRUEBA: Dime qué hace el chico (el chico deja/pone su chaqueta/casaca } \\
\text { encima de/en el sillón). }\end{array}$ \\
\hline \multirow[t]{2}{*}{5} & 2 & 47 & INTRODUCCIÓN: Mira este dibujo. \\
\hline & & & $\begin{array}{l}\text { PRUEBA: Dime qué cosa pone la niña y dónde la pone (la niña pone el libro } \\
\text { en/dentro de la mochila). }\end{array}$ \\
\hline \multirow[t]{2}{*}{5} & 4 & 47 & INTRODUCCIÓN: Mira este dibujo. \\
\hline & & & $\begin{array}{l}\text { PRUEBA: Dime qué hace el chico (el chico saca el oso de la canasta/pone el } \\
\text { oso en la canasta). }\end{array}$ \\
\hline \multirow[t]{2}{*}{5} & 5 & 49 & INTRODUCCIÓN: Ahora mira este dibujo. \\
\hline & & & PRUEBA: Dime qué hace este hombre (el hombre coge el martillo de la repisa). \\
\hline \multirow[t]{2}{*}{5} & 6 & 49 & INTRODUCCIÓN: Mira este dibujo. \\
\hline & & & $\begin{array}{l}\text { PRUEBA: Dime qué cosa pone la mujer y dónde la pone (la mujer pone al } \\
\text { niño en la colcha). }\end{array}$ \\
\hline
\end{tabular}




\begin{tabular}{|c|c|c|c|}
\hline Bloque & Ítem & Pág. & Modificación \\
\hline \multirow[t]{2}{*}{8} & 3 & 77 & INTRODUCCIÓN: Esta canasta está llena. \\
\hline & & & $\begin{array}{l}\text { PRUEBA: Háblame de la canasta que hay en tu dibujo (esta canasta no está } \\
\text { llena). }\end{array}$ \\
\hline \multirow[t]{2}{*}{8} & 8 & 81 & INTRODUCCIÓN: Este choclo está cocido. \\
\hline & & & $\begin{array}{l}\text { PRUEBA: Dime si el choclo de tu dibujo está cocido (este choclo no está } \\
\text { cocido). }\end{array}$ \\
\hline \multirow[t]{2}{*}{9} & 2 & 87 & INTRODUCCIÓN: En la vitrina de mi dibujo hay rosas. \\
\hline & & & $\begin{array}{l}\text { PRUEBA: Dime si hay alguna rosa en la vitrina de tu dibujo (no, no hay ningu- } \\
\text { na). }\end{array}$ \\
\hline \multirow[t]{2}{*}{9} & 6 & 89 & INTRODUCCIÓN: Las botas de este señor están en el closet. \\
\hline & & & $\begin{array}{l}\text { PRUEBA: Dime si en tu dibujo ves las botas por alguna parte (no, no veo las } \\
\text { botas por ninguna parte). }\end{array}$ \\
\hline \multirow[t]{2}{*}{9} & 8 & 91 & $\begin{array}{l}\text { INTRODUCCIÓN: Aquí hay alguien esperando para poder llamar por teléfo- } \\
\text { no. }\end{array}$ \\
\hline & & & $\begin{array}{l}\text { PRUEBA: Dime si en tu dibujo hay alguien esperando para poder llamar por } \\
\text { teléfono (no, no hay nadie). }\end{array}$ \\
\hline \multirow[t]{2}{*}{9} & 10 & 91 & INTRODUCCIÓN: En la canasta hay muchas manzanas. \\
\hline & & & $\begin{array}{l}\text { PRUEBA: Dime si hay alguna manzana en la canasta de tu dibujo (no, no hay } \\
\text { ninguna). }\end{array}$ \\
\hline \multirow[t]{2}{*}{10} & 9 & 101 & INTRODUCCIÓN: Sergio llama a María. \\
\hline & & & $\begin{array}{l}\text { PRUEBA: Explícamelo empezando la frase con "María" (María es llamada } \\
\text { por Sergio). }\end{array}$ \\
\hline \multirow[t]{2}{*}{10} & 10 & 101 & INTRODUCCIÓN: El policía resondra a las niñas. \\
\hline & & & $\begin{array}{l}\text { PRUEBA: Explícamelo empezando con la frase "Las niñas" (las niñas son } \\
\text { resondradas por el policía). }\end{array}$ \\
\hline \multirow[t]{5}{*}{11} & Demo & 105 & $\begin{array}{l}\text { INTRODUCCIÓN: Mira este dibujo. (señalar la ilustración de la izquierda) El } \\
\text { chico come (señalar). La chica come. }\end{array}$ \\
\hline & & & Para decir que ambos comen, podemos decir: El chico y la chica comen. \\
\hline & & & PRUEBA: Explícame este dibujo otra vez (el chico y la chica comen). \\
\hline & & & $\begin{array}{l}\text { INTRODUCCIÓN: Ahora mira este dibujo (señalar el de la derecha). El chico } \\
\text { come una hamburguesa. También come papas fritas. Ya que come las dos } \\
\text { cosas podemos decir: El chico come una hamburguesa y papas fritas. }\end{array}$ \\
\hline & & & $\begin{array}{l}\text { PRUEBA: Explícame este dibujo otra vez (el chico come una hamburguesa y } \\
\text { papas fritas) }\end{array}$ \\
\hline \multirow[t]{2}{*}{11} & 8 & 111 & INTRODUCCIÓN: Mira lo que hacen estos niños. \\
\hline & & & PRUEBA: Explícamelo en una sola frase (los niños toman leche y jugo). \\
\hline \multirow[t]{2}{*}{11} & 9 & 111 & INTRODUCCIÓN: Mira lo que hacen estos niños. \\
\hline & & & PRUEBA: Explícamelo en una sola frase (los niños juegan basket y fútbol). \\
\hline \multirow[t]{2}{*}{12} & 2 & 117 & INTRODUCCIÓN: Mira las dos cosas que hace este señor. \\
\hline & & & $\begin{array}{l}\text { PRUEBA: Explícame ambas cosas en una sola frase (este señor lava y seca } \\
\text { el carro). }\end{array}$ \\
\hline 12 & 3 & 11 & INTRODUCCIÓN: Mira las dos cosas que hace el chico. \\
\hline
\end{tabular}

PRUEBA: Explícame ambas cosas en una sola frase (el chico barre y bota/recoge y bota las hojas).

129121 INTRODUCCIÓN: Mira este carro (señalar el viejo). Este dibujo muestra dos cosas acerca de él. 


Bloque Ítem Pág. Modificación

PRUEBA: Dime las dos cosas en una sola frase (el carro es viejo y destartalado).

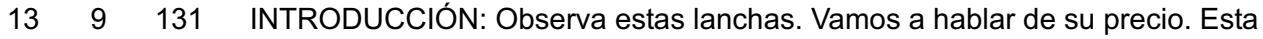
lancha es bastante cara, ésta es cara y ésta muy cara.

PRUEBA: Vamos a comparar esta lancha (señalar la $2^{\mathrm{a}}$ ) con ésta (señalar la $\left.1^{\mathrm{a}}\right)$. Esta lancha es ... (más cara que ésta). Ahora la compararemos con esta otra (señalar la $3^{a}$ ). Esta lancha es ... (menos cara que ésta).

14 Demo 135 INTRODUCCIÓN: Mira estos dibujos (señalar el dibujo de la izquierda). Estos niños almuerzan en el campo. Y ésta es la razón (señalar el dibujo de la derecha): Hace sol.

PRUEBA: Puedo decir lo que hicieron los niños y la razón de ello en una sola frase. ¿Puedes ayudarme a terminarla? Los niños almorzaron en el campo porque ... (hacía sol).

INTRODUCCIÓN: También podemos explicar estos dibujos de otra manera. Este dibujo (señalar el dibujo de la derecha) te enseña lo que sucede: hace sol. Y este otro (señalar el dibujo de la izquierda) lo que los niños harán: irán a almorzar al campo.

PRUEBA: Vamos a explicarlo en una sola frase (si hace sol, los niños irán a almorzar al campo)

141135 INTRODUCCIÓN: Observa estos dibujos.

PRUEBA: En una sola frase explícame lo que hizo la niña y la razón de ello (la niña se puso las botas porque nevaba/llovía).

142137 INTRODUCCIÓN: Observa al niño de este dibujo.

PRUEBA: Dime qué hizo y por qué (el chico se puso el abrigo/ la casaca porque llovía).

1410141 INTRODUCCIÓN: Mira estos dibujos.

PRUEBA: Explícame ambos en una sola frase (si los niños terminan la comida, podrán tomar helado de postre).

151145 INTRODUCCIÓN: Mira este dibujo. Tiene dos partes. En ésta se muestra lo que la chica hizo primero (señalar), y en esta otra lo que hizo al final (señalar).

PRUEBA: ¿Puedes explicarme lo que hizo la chica en una sola frase? Empieza con la palabra "después" (después de lavarse las manos, la chica se come un pan).

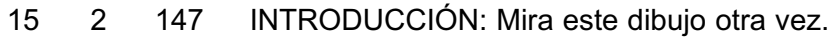

PRUEBA: Esta vez quiero que utilices la palabra "antes" cuando me expliques lo que ocurre (la chica se lava las manos antes de comerse el pan).

17 Demo 165 INTRODUCCIÓN: Este niño ha ido a comprar con su padre. Ha visto una chompa que le gustaba. Sin embargo, este dibujo nos muestra que su padre le ha comprado una casaca.

PRUEBA: Yo quiero explicar ambas cosas en una frase. Ayúdame. El niño quería una chompa, "pero" ... (le han comprado una casaca).

INTRODUCCIÓN: También puedo utilizar la palabra "aunque" para explicar las dos cosas.

PRUEBA: Puedo decir: "Aunque" el niño quería una chompa ... (le han comprado una casaca). 


\begin{tabular}{|c|c|c|c|}
\hline Bloque & Ítem & Pág. & Modificación \\
\hline & & & $\begin{array}{l}\text { Recuerda: el niño quería una chompa, pero le han comprado una casaca. } \\
\text { También podemos decir: Aunque el niño quería una chompa, le han compra- } \\
\text { do una casaca. }\end{array}$ \\
\hline \multirow[t]{2}{*}{17} & 7 & 169 & $\begin{array}{l}\text { INTRODUCCIÓN: Este niño quería ir al zoológico. Sus padres querían ir a } \\
\text { almorzar. El niño ha ido con ellos. }\end{array}$ \\
\hline & & & $\begin{array}{l}\text { PRUEBA: Explícame lo que ha ocurrido en una frase, utilizando la palabra } \\
\text { "pero" (el niño quería ir al zoológico, pero ha ido a almorzar). }\end{array}$ \\
\hline \multirow[t]{2}{*}{17} & 8 & 171 & INTRODUCCIÓN: Miremos otra vez estos dibujos. \\
\hline & & & $\begin{array}{l}\text { PRUEBA: Explícame otra vez estos dibujos, pero esta vez utiliza la palabra } \\
\text { "aunque" (aunque el niño quería ir al zoológico, ha ido a almorzar). }\end{array}$ \\
\hline \multirow[t]{2}{*}{17} & 9 & 171 & $\begin{array}{l}\text { INTRODUCCIÓN: Este niño quería ir a la piscina. Este dibujo nos muestra } \\
\text { que se ha quedado en casa haciendo las tareas. }\end{array}$ \\
\hline & & & $\begin{array}{l}\text { PRUEBA: Explícame en una sola frase estas dos cosas, utilizando la palabra } \\
\text { "pero" (el niño quería ir a la piscina, pero se ha quedado en casa haciendo } \\
\text { las tareas). }\end{array}$ \\
\hline \multirow[t]{2}{*}{17} & 10 & 171 & INTRODUCCIÓN: Mira otra vez los dibujos. \\
\hline & & & $\begin{array}{l}\text { PRUEBA: Explícame otra vez lo que ha ocurrido, pero ahora utiliza la palabra } \\
\text { "aunque" (aunque el niño quería ir a la piscina, se ha quedado en casa } \\
\text { haciendo las tareas). }\end{array}$ \\
\hline \multirow[t]{2}{*}{18} & 1 & 175 & INTRODUCCIÓN: Veo un carro que tiene una llanta baja. \\
\hline & & & $\begin{array}{l}\text { PRUEBA: Ahora dime lo que ves. Empieza con "Veo..." (veo una bicicleta que } \\
\text { tiene las llantas bajas). }\end{array}$ \\
\hline \multirow[t]{2}{*}{18} & 4 & 177 & INTRODUCCIÓN: Veo una niña que come pizza de una caja. \\
\hline & & & $\begin{array}{l}\text { PRUEBA: Dime qué ves. Empieza con "Veo..." (veo un niño que toma leche } \\
\text { de un envase). }\end{array}$ \\
\hline \multirow[t]{2}{*}{18} & 5 & 179 & INTRODUCCIÓN: Veo un chico que lleva polo de rayas. \\
\hline & & & $\begin{array}{l}\text { PRUEBA: Dime qué ves. Empieza con "Veo..." (veo un chico que lleva pan- } \\
\text { talones de rayas). }\end{array}$ \\
\hline
\end{tabular}




\section{APÉNDICE 2}

Tabla 12

Baremos Normativos en Percentiles (Pc) para la Puntuación Directa (PD) en el Módulo de Sintaxis de la Batería de Lenguaje Objetiva y Criterial (BLOC) por Grupo de Edad

\begin{tabular}{|c|c|c|c|c|c|c|c|c|c|c|c|}
\hline \multirow[t]{2}{*}{$\mathrm{Pc}$} & \multicolumn{3}{|c|}{ Puntaje Directo } & \multirow[t]{2}{*}{$\mathrm{Pc}$} & \multicolumn{3}{|c|}{ Puntaje Directo } & \multirow[t]{2}{*}{$\mathrm{Pc}$} & \multicolumn{3}{|c|}{ Puntaje Directo } \\
\hline & 6 años & 7 años & 8 años & & 6 años & 7 años & 8 años & & 6 años & 7 años & 8 años \\
\hline 99 & 118 & 130 & 138 & 66 & 90 & - & - & 33 & 68 & 82 & - \\
\hline 98 & - & - & - & 65 & - & - & - & 32 & 67 & - & 94 \\
\hline 97 & - & 129 & - & 64 & - & - & 110 & 31 & 66 & 81 & 93 \\
\hline 96 & 117 & 128 & 137 & 63 & - & 91 & - & 30 & - & 80 & 92 \\
\hline 95 & 116 & 126 & 134 & 62 & - & - & - & 29 & - & 78 & 91 \\
\hline 94 & 115 & 124 & 129 & 61 & - & - & - & 28 & 65 & 77 & 90 \\
\hline 93 & 114 & 121 & 123 & 60 & - & - & - & 27 & - & - & - \\
\hline 92 & - & 120 & 120 & 59 & 89 & - & - & 26 & - & - & 89 \\
\hline 91 & - & 119 & 117 & 58 & 88 & - & - & 25 & - & - & 88 \\
\hline 90 & - & - & - & 57 & - & - & 109 & 24 & - & 76 & - \\
\hline 89 & 113 & 118 & 116 & 56 & 87 & 90 & - & 23 & - & - & - \\
\hline 88 & 112 & 117 & - & 55 & 86 & 89 & 108 & 22 & 64 & 75 & 87 \\
\hline 87 & 111 & 115 & 115 & 54 & - & 88 & - & 21 & 63 & 74 & 85 \\
\hline 86 & - & 113 & - & 53 & 85 & - & 107 & 20 & 62 & - & 84 \\
\hline 85 & - & 111 & - & 52 & - & 87 & - & 19 & - & 73 & - \\
\hline 84 & - & 109 & - & 51 & - & 86 & 106 & 18 & 61 & - & - \\
\hline 83 & 110 & - & - & 50 & - & - & - & 17 & 60 & 72 & 83 \\
\hline 82 & 108 & - & 114 & 49 & 83 & 85 & - & 16 & 57 & - & 82 \\
\hline 81 & 105 & - & - & 48 & 80 & - & - & 15 & 55 & 71 & 81 \\
\hline 80 & 102 & 108 & - & 47 & 79 & - & - & 14 & - & - & 80 \\
\hline 79 & 100 & 107 & - & 46 & - & - & 105 & 13 & 54 & - & - \\
\hline 78 & 99 & - & 113 & 45 & - & - & 104 & 12 & - & 70 & - \\
\hline 77 & 97 & - & - & 44 & - & - & 103 & 11 & 53 & 69 & - \\
\hline 76 & 96 & 106 & - & 43 & - & 84 & 102 & 10 & - & - & 79 \\
\hline 75 & 95 & 104 & - & 42 & 78 & - & 101 & 9 & 51 & 68 & 78 \\
\hline 74 & - & 103 & - & 41 & 75 & - & - & 8 & 50 & 67 & 77 \\
\hline 73 & - & 102 & - & 40 & 73 & 83 & 100 & 7 & 49 & - & 75 \\
\hline 72 & - & - & - & 39 & 72 & - & 98 & 6 & 48 & - & 74 \\
\hline 71 & 94 & - & 112 & 38 & 71 & - & - & 5 & 47 & - & 73 \\
\hline 70 & 93 & 101 & - & 37 & - & - & - & 4 & 41 & 66 & 70 \\
\hline 69 & 92 & 98 & - & 36 & - & - & - & 3 & 34 & 64 & 66 \\
\hline 68 & 91 & 94 & - & 35 & - & - & 96 & 2 & 31 & 63 & 63 \\
\hline 67 & - & 92 & 111 & 34 & 69 & - & 95 & 1 & - & - & - \\
\hline
\end{tabular}


Tabla 13

Baremos Normativos en Percentiles (Pc) para la Puntuación Directa (PD) en los Bloques del Módulo de Sintaxis de la Batería de Lenguaje Objetiva y Criterial (BLOC) para el grupo de 6 años

\begin{tabular}{|c|c|c|c|c|c|c|c|c|c|c|c|c|c|c|c|c|c|c|}
\hline PD & B1 & B2 & B3 & B4 & B5 & B6 & B7 & B8 & B9 & B10 & B11 & B12 & B13 & B14 & B15 & B16 & B17 & B18 \\
\hline 10 & 99 & 99 & 99 & 99 & 99 & 99 & 99 & 99 & 99 & 99 & 99 & 99 & 99 & 99 & 99 & 99 & 99 & 99 \\
\hline 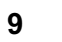 & 68 & 88 & 91 & 86 & 91 & 99 & 88 & 88 & 96 & 99 & 99 & 99 & 99 & 99 & 96 & 96 & 79 & 99 \\
\hline 8 & 46 & 43 & 83 & 58 & 81 & 99 & 79 & 83 & 78 & 99 & 96 & 99 & 99 & 99 & 95 & 92 & 78 & 99 \\
\hline 7 & 45 & 38 & 66 & 38 & 68 & 88 & 78 & 66 & 68 & 99 & 95 & 99 & 96 & 99 & 89 & 91 & 71 & 99 \\
\hline \multicolumn{19}{|c|}{$70 \%$} \\
\hline 6 & 43 & 26 & 46 & 23 & 31 & 56 & 63 & 53 & 58 & 99 & 88 & 99 & 94 & 99 & 88 & 90 & 66 & 99 \\
\hline 5 & 41 & 18 & 26 & 13 & 21 & 41 & 53 & 38 & 48 & 99 & 86 & 99 & 93 & 96 & 83 & 83 & 53 & 99 \\
\hline 4 & 33 & 11 & 13 & 6 & 13 & 21 & 33 & 23 & 43 & 99 & 73 & 99 & 91 & 76 & 71 & 76 & 31 & 56 \\
\hline 3 & 26 & 6 & 8 & 5 & 3 & 6 & 26 & 11 & 18 & 96 & 63 & 99 & 81 & 66 & 61 & 61 & 28 & 41 \\
\hline 2 & 23 & 4 & 3 & 0 & 0 & 3 & 13 & 10 & 16 & 95 & 43 & 93 & 61 & 38 & 53 & 53 & 26 & 24 \\
\hline 1 & 18 & 3 & 0 & 0 & 0 & 0 & 11 & 0 & 8 & 93 & 18 & 81 & 46 & 26 & 48 & 43 & 18 & 23 \\
\hline 0 & 0 & 0 & 0 & 0 & 0 & 0 & 3 & 0 & 3 & 83 & 6 & 61 & 31 & 16 & 41 & 36 & 13 & 8 \\
\hline
\end{tabular}

Tabla 14

Baremos Normativos en Percentiles (Pc) para la Puntuación Directa (PD) en los Bloques del Módulo de Sintaxis de la Batería de Lenguaje Objetiva y Criterial (BLOC) para el grupo de 7 años

\begin{tabular}{lllllllllllllllllll}
\hline $\mathrm{PD}$ & $\mathrm{B} 1$ & $\mathrm{~B} 2$ & $\mathrm{~B} 3$ & $\mathrm{~B} 4$ & $\mathrm{~B} 5$ & $\mathrm{~B} 6$ & $\mathrm{~B} 7$ & $\mathrm{~B} 8$ & $\mathrm{~B} 9$ & $\mathrm{~B} 10$ & $\mathrm{~B} 11$ & $\mathrm{~B} 12$ & $\mathrm{~B} 13$ & $\mathrm{~B} 14$ & $\mathrm{~B} 15$ & $\mathrm{~B} 16$ & $\mathrm{~B} 17$ & $\mathrm{~B} 18$ \\
\hline $\mathbf{1 0}$ & 99 & 99 & 99 & 99 & 99 & 99 & 99 & 99 & 99 & 99 & 99 & 99 & 99 & 99 & 99 & 99 & 99 & 99 \\
$\mathbf{9}$ & 61 & 77 & 96 & 80 & 99 & 99 & 80 & 91 & 96 & 99 & 99 & 99 & 99 & 99 & 99 & 96 & 77 & 99 \\
$\mathbf{8}$ & 33 & 56 & 77 & 40 & 89 & 89 & 68 & 82 & 89 & 99 & 99 & 99 & 99 & 99 & 94 & 94 & 70 & 99 \\
$\mathbf{7}$ & 24 & 26 & 66 & 15 & 61 & 75 & 59 & 63 & 87 & 99 & 96 & 99 & 97 & 95 & 87 & 87 & 66 & 99 \\
$70 \%$ & & & & & & & & & & & & & & & & & & \\
$\mathbf{6}$ & 17 & 17 & 47 & 3 & 36 & 61 & 52 & 47 & 68 & 96 & 91 & 97 & 95 & 94 & 77 & 84 & 61 & 99 \\
$\mathbf{5}$ & 13 & 6 & 26 & 0 & 8 & 45 & 45 & 31 & 50 & 94 & 82 & 95 & 91 & 93 & 61 & 80 & 56 & 99 \\
$\mathbf{4}$ & 12 & 5 & 12 & 0 & 0 & 22 & 31 & 19 & 29 & 93 & 68 & 91 & 80 & 63 & 50 & 63 & 31 & 59 \\
$\mathbf{3}$ & 11 & 0 & 0 & 0 & 0 & 15 & 22 & 10 & 19 & 91 & 43 & 89 & 73 & 43 & 40 & 56 & 20 & 33 \\
$\mathbf{2}$ & 9 & 0 & 0 & 0 & 0 & 5 & 15 & 5 & 10 & 87 & 22 & 87 & 56 & 26 & 36 & 43 & 19 & 22 \\
$\mathbf{1}$ & 8 & 0 & 0 & 0 & 0 & 0 & 10 & 3 & 8 & 84 & 5 & 75 & 43 & 19 & 31 & 36 & 10 & 10 \\
$\mathbf{0}$ & 0 & 0 & 0 & 0 & 0 & 0 & 5 & 0 & 0 & 80 & 3 & 59 & 38 & 8 & 24 & 33 & 8 & 8 \\
\hline
\end{tabular}


Tabla 15

Baremos Normativos en Percentiles (Pc) para la Puntuación Directa (PD) en los Bloques del Módulo de Sintaxis de la Batería de Lenguaje Objetiva y Criterial (BLOC) para el grupo de 8 años

\begin{tabular}{llllllllllllllllllll}
\hline $\mathrm{PD}$ & $\mathrm{B} 1$ & $\mathrm{~B} 2$ & $\mathrm{~B} 3$ & $\mathrm{~B} 4$ & $\mathrm{~B} 5$ & $\mathrm{~B} 6$ & $\mathrm{~B} 7$ & $\mathrm{~B} 8$ & $\mathrm{~B} 9$ & $\mathrm{~B} 10$ & $\mathrm{~B} 11$ & $\mathrm{~B} 12$ & $\mathrm{~B} 13$ & $\mathrm{~B} 14$ & $\mathrm{~B} 15$ & $\mathrm{~B} 16$ & $\mathrm{~B} 17$ & $\mathrm{~B} 18$ \\
\hline $\mathbf{1 0}$ & 99 & 99 & 99 & 99 & 99 & 99 & 99 & 99 & 99 & 99 & 99 & 99 & 99 & 99 & 99 & 99 & 99 & 99 \\
$\mathbf{9}$ & 55 & 69 & 99 & 69 & 96 & 99 & 76 & 82 & 92 & 99 & 99 & 99 & 99 & 99 & 92 & 96 & 71 & 99 \\
$\mathbf{8}$ & 28 & 44 & 73 & 39 & 78 & 94 & 71 & 69 & 80 & 96 & 94 & 99 & 99 & 96 & 87 & 82 & 57 & 99 \\
$\mathbf{7}$ & 21 & 21 & 55 & 14 & 44 & 78 & 60 & 39 & 60 & 94 & 93 & 95 & 94 & 92 & 82 & 76 & 51 & 99 \\
$70 \%$ & -19 & & & & & & & & & & & & & & \\
$\mathbf{6}$ & 19 & 7 & 44 & 0 & 19 & 53 & 48 & 23 & 46 & 92 & 87 & 94 & 85 & 88 & 67 & 69 & 48 & 99 \\
$\mathbf{5}$ & 17 & 0 & 21 & 0 & 7 & 23 & 39 & 19 & 28 & 85 & 78 & 93 & 71 & 86 & 60 & 62 & 32 & 99 \\
$\mathbf{4}$ & 12 & 0 & 12 & 0 & 3 & 14 & 23 & 10 & 17 & 80 & 62 & 89 & 62 & 62 & 46 & 48 & 12 & 51 \\
$\mathbf{3}$ & 10 & 0 & 3 & 0 & 0 & 7 & 17 & 6 & 10 & 78 & 44 & 85 & 46 & 39 & 35 & 39 & 10 & 28 \\
$\mathbf{2}$ & 8 & 0 & 0 & 0 & 0 & 5 & 14 & 5 & 5 & 76 & 17 & 76 & 30 & 19 & 26 & 35 & 5 & 19 \\
$\mathbf{1}$ & 7 & 0 & 0 & 0 & 0 & 0 & 12 & 3 & 3 & 73 & 7 & 48 & 21 & 12 & 19 & 28 & 3 & 12 \\
$\mathbf{0}$ & 0 & 0 & 0 & 0 & 0 & 0 & 10 & 0 & 2 & 67 & 3 & 30 & 7 & 3 & 10 & 21 & 2 & 7 \\
\hline
\end{tabular}

